\title{
Patrones, capataces y trabajadores en la industria gráfica. Un estudio de caso: Ortega y Radaelli, 1901-1921
}

\author{
María Silvia Badoza*
}

\section{Resumen}

En este estudio se aborda el tránsito de la pequeña producción al taller gráfico moderno. El análisis está dirigido a comprender los cambios en la industria y explicar, en ese contexto, las modificaciones en la composición de la mano de obra y los efectos sobre la calificación y el lugar ocupado por los trabajadores de oficio. Finalmente se presentan algunas notas sobre el desarrollo de la estrategia sindical y el grado de negociación alcanzado con los empresarios en el modo de gestión del ingreso de los obreros.

\section{Abstract}

This article focuses on the transition experienced by small workshops transforming themselves into the modern printing establishment. It tries to understand the changes in the printing industry and to explain, in this context, the transformation of the work force and its effects on the qualification and roles of the craftsmen. The final part analyses the development of a strategy aimed at controlling the recruitment of the work force by the workers.
Palabras clave:

Empresa, tecnología, mano de obra, sindicalismo, relaciones laborales.
Fecha de recepción: marzo de 2000

Fecha de aceptación: septiembre de 2000

* Profesional adjunta de la Carrera del Personal de Apoyo al Desarrollo e Investigación del Consejo Nacional de Investigaciones Científicas y Técnicas (CONICET) en el Instituto de Historia Argentina y Americana "Dr. Emilio Ravignani" en su Programa de Estudios de Historia Económica y Social Americana (PEHESA), Facultad de Filosofía y Letras, Universidad de Buenos Aires. Correo electrónico: silviabadoza@fibertel.com.ar 


\section{INTRODUCCIÓN}

A partir de la década de los ochenta del siglo XIX se produjo una expansión en la cantidad de talleres de imprenta y la ciudad de Buenos Aires se transformó en el principal centro de producción y consumo de las artes gráficas. Desde esa fecha, la rama industrial gráfica asistió a un cambio de escala en un doble sentido: el aumento en el número de talleres de pequeña producción y el crecimiento de otros a dimensiones hasta entonces desconocidas. También cambió la escala de los trabajadores empleados en esta industria en expansión; en los grandes talleres las transformaciones estaban relacionadas con la contratación de una fuerza laboral extensa en un solo emplazamiento. Paralelamente, se produjo una concentración de talleres multigráficos desde la Av. de Mayo hasta la zona sudeste de la ciudad; en el barrio de Barracas y a pocas cuadras de distancia unos de otros, estaban ubicados: Compañía Sudamericana de Billetes de Banco, Peuser, Kraft y la Compañía General de Fósforos.

A la hora de estudiar y analizar la configuración del sector artes gráficas tenemos que tener en cuenta la amplia gama de productos. Cada uno de ellos (periódicos, tarjetería, libros, catálogos y folletería) daba lugar a diversos desarrollos del proceso de trabajo y formas organizativas de las empresas, ya sea que en ellas se realizaran todas las fases del proceso (composición, impresión y encuadernación) o solamente una parte del mismo. No sólo las características de los productos, sino tam- bién la calidad y los volúmenes producidos eran significativos en el momento de establecer las formas empresariales, que iban desde establecimientos multigráficos, en general de gran envergadura, pasando por aquellos especializados en ciertos productos, por ejemplo folletería, hasta el pequeño taller disperso por toda la ciudad, dedicado a cualquier tipo de trabajo pero siempre en escaso volumen. ${ }^{1}$

El periodo que estamos analizando no sólo estuvo marcado por los cambios en la producción, también hubo modificaciones en el ámbito de la agremiación. Desde los primeros años del siglo $\mathrm{xx}$ fueron conformándose dos fuertes y perdurables organizaciones, que representaron los intereses patronales y de los trabajadores. La Sección Artes Gráficas de la UIA, formada en 1904, concentraba a los propietarios de imprentas. La Federación Gráfica Bonaerense, organización de los trabajadores, fue el resultado de la unificación de cuatro organizaciones previas: la Sección Francesa y Alemana de las Artes Gráficas, la Federación de las Artes Gráficas (anarquista) y la Unión Gráfica (socialista). ${ }^{2}$

Estas dos últimas eran las más importantes por el número de afiliados e influencia en el conjunto de los trabajadores en el momento de plantear una reivindicación. El 3 de mayo de 1907 quedó constituida la Federación Gráfica Bonaerense, desde entonces fueron incorporándose a ella, de manera fede-

${ }^{1}$ Bilbao, "Procesos", 1990, pp. 3-4.

2 Para las formas organizativas de los trabajadores gráficos en el anterior periodo véase, Bacloza, "Typographical", 1992, pp. 72-90. 
rada, todas las sociedades de resistencia de los distintos oficios. El sindicalismo de oficio intentaba, en momentos de cambios de la industria gráfica, negociar la tarifa salarial y las condiciones de trabajo. Hasta la huelga de 1906, que paralizó por más de un mes a las imprentas de Buenos Aires, los propietarios gráficos tuvieron un comportamiento reticente para entrar en tratativas con el sindicalismo. Sin embargo, desde 1907 hasta 1919 trabajadores y empresarios gráficos abrieron espacios de negociación. Entre esas dos fechas las normas laborales y las tarifas de salarios estándares fueron especificadas en un convenio, alcanzándose en las artes gráficas una regulación temprana de las relaciones laborales. ${ }^{3}$

En este artículo analizaré uno de los talleres gráficos más importantes de la ciudad de Buenos Aires. ${ }^{4}$ Desa-

${ }^{3}$ Ricardo Falcón señaló que a partir del año 1902 hubo modificaciones en la relación entre trabajadores y patrones. Desde la perspectiva de los trabajadores y las sociedades de resistencia, el cambio más importante fue la aceptación del diálogo con los empresarios y el establecimiento de ciertas reglas de juego para resolver los conflictos obrero-patronales. Una tendencia que daría como resultado la firma de los primeros convenios colectivos y cuyo caso más ilustrativo fue el de los tipógrafos. Véase Falcón, "Mundo", 1990 , p. 356.

${ }^{4}$ Nuestro trabajo de recuperación y preservación del Archivo Empresarial "Compañía General de Fósforos y Fabril Financiera" nos proporcionó fuentes documentales empresariales pertenecientes al establecimiento Ortega y Radaelli. El archivo empresario está ubicado en el Programa de Estudios de Historia Económica y Social Americana (PEHESA) del Instituto "Emilio Ravignani", Facultad de Filosofía y Letras-UBA. rrolló su actividad como Ortega y Radaelli entre 1901 y 1911; con posterioridad a esa fecha y hasta 1921, como Ricardo Radaelli; en este último año fue adquirido por la Compañía General de Fósforos. Estudiaré la composición de su mano de obra a partir de vincular tres cuestiones: los cambios en la magnitud del establecimiento gráfico, la introducción de nuevas tecnologías en los diversos procesos de trabajo y la aplicación de las normas establecidas en el convenio. 5 Además, indagaré sobre la incorporación de trabajadores calificados, pero ya no pertenecientes a los oficios de la imprenta, y también, la demanda de peones. En ese contexto de cambios, analizaré el surgimiento del sector de supervisión: regentes, encargados, jefes y capataces de sección. En la segunda parte estudiaré las modalidades de ingreso de la mano de obra. Me propuse reconstruir la política de contratación impulsada por los propietarios, como también la reelaboración por parte de los trabajar dores de las estrategias patronales y los esfuerzos por regular sindicalmente la contratación para controlar quiénes ingresaban al establecimiento y así garantizar la incorporación de obreros capaces de llevar adelante la defensa del oficio.

${ }^{5} \mathrm{El}$ artículo es parte de una investigación en desarrollo: "Empresas, trabajo y sindicalismo: el Sector de Artes Gráficas, 1907-1930". En la investigación se estudia la experiencia de los trabajadores gráficos en un periodo de fuerte cambio tecnológico: la vinculación entre los procesos productivos, el conflicto laboral y los modos organizativos obreros. 
HACIA EL GRAN TALLER:

ORTEGA Y RADAELLI

En el proceso de crecimiento de la industria gráfica ubicamos la constitución del establecimiento de Fausto Ortega y Ricardo Radaelli. Fundado en 1901 , inicialmente estuvo ubicado en la calle Perú 662-672. En este mismo edificio había funcionado, hasta principios de 1901, la imprenta de Ortega y Millán. ${ }^{6}$

A fines del año 1907 la firma Ortega y Radaelli había finalizado la construcción de un gran edificio de tres pisos y subsuelo, ubicado en Paseo Colón 1244 al 1276, para trasladar el taller de artes gráficas. Los dueños optaron por realizar inversiones en instalaciones edilicias y tecnológicas con el objetivo de ampliar sus negocios.

El nuevo edificio ocupó una superficie de 4235 metros cuadrados; las

${ }^{6}$ Ortega había fundado en la década de 1880 el primer taller de fotograbado en nuestro país. Fausto Ortega había comenzado en 1877 el aprendizaje del fotograbado en Barcelona, luego fundó un taller en Madrid, el primero de grabado por el sistema fotográfico. Se trasladó a París, donde trabajó en dos talleres muy importantes, prosiguió su perfeccionamiento en Londres y para 1885 instaló un taller de fotograbado en Buenos Aires. Ortega compartió con otros empresarios gráficos del siglo XIX una trayectoria de formación en Europa y posterior traslado a nuestro país procurando nuevos horizontes, en momentos en que el sector de las artes gráficas comenzaba su gran desarrollo. Fausto Ortega fue miembro de la Sección Artes Gráficas de la Unión Industrial Argentina desde su formación en 1904; también fue integrante de la comisión encargada de la redacción del reglamento de la sección y vocal de la primera comisión. inversiones en modernas tecnologías fueron importantes, y totalizaron la incorporación de 87 máquinas. ${ }^{7} \mathrm{La}$ integración de los linotipos en la sala de composición permitió eliminar el desfasaje que se producía entre la velocidad de las rotativas y el lento proceso de composición manual. Por otro lado, la incorporación de los equipos de estereotipia permitió duplicar páginas sin tener que componer nuevamente los tipos, mientras que las rotativas y prensas, para la impresión de trabajos tipográficos y litográficos, aseguraron una rápida impresión y un aumento de la tirada diaria. El proceso de mecanización también afectó a la encuadernación, con la incorporación de máquinas cosedoras de pliegos, abrochadoras, guillotinas y dobladoras automáticas. Sin embargo, en las artes gráficas no todo fue mecanización; al igual que en otras ramas industriales, hubo una coexistencia de procesos manuales y mecánicos. Por ejemplo, durante el periodo en estudio, en la sala de composición del taller de Ortega y Radaelli no se produjo la exclusión del proceso manual; las cajas tipográficas y los linotipos estaban ubicados en la misma sección.

Los cambios no finalizaron allí; además de mudarse al nuevo edificio y mecanizarse, continuaron con la integración de las distintas ramas de las artes gráficas bajo un mismo techo y en cada una de ellas de todas las fases

7 Parte de la tecnología incorporada fue la siguiente: dos rotativas de ilustración en negro $y$ colores y de formato variable, siete máquinas planas con ponepliego automático, nueve máquinas de gran formato de litografía, 17 de tipografía y ocho linotipos. 


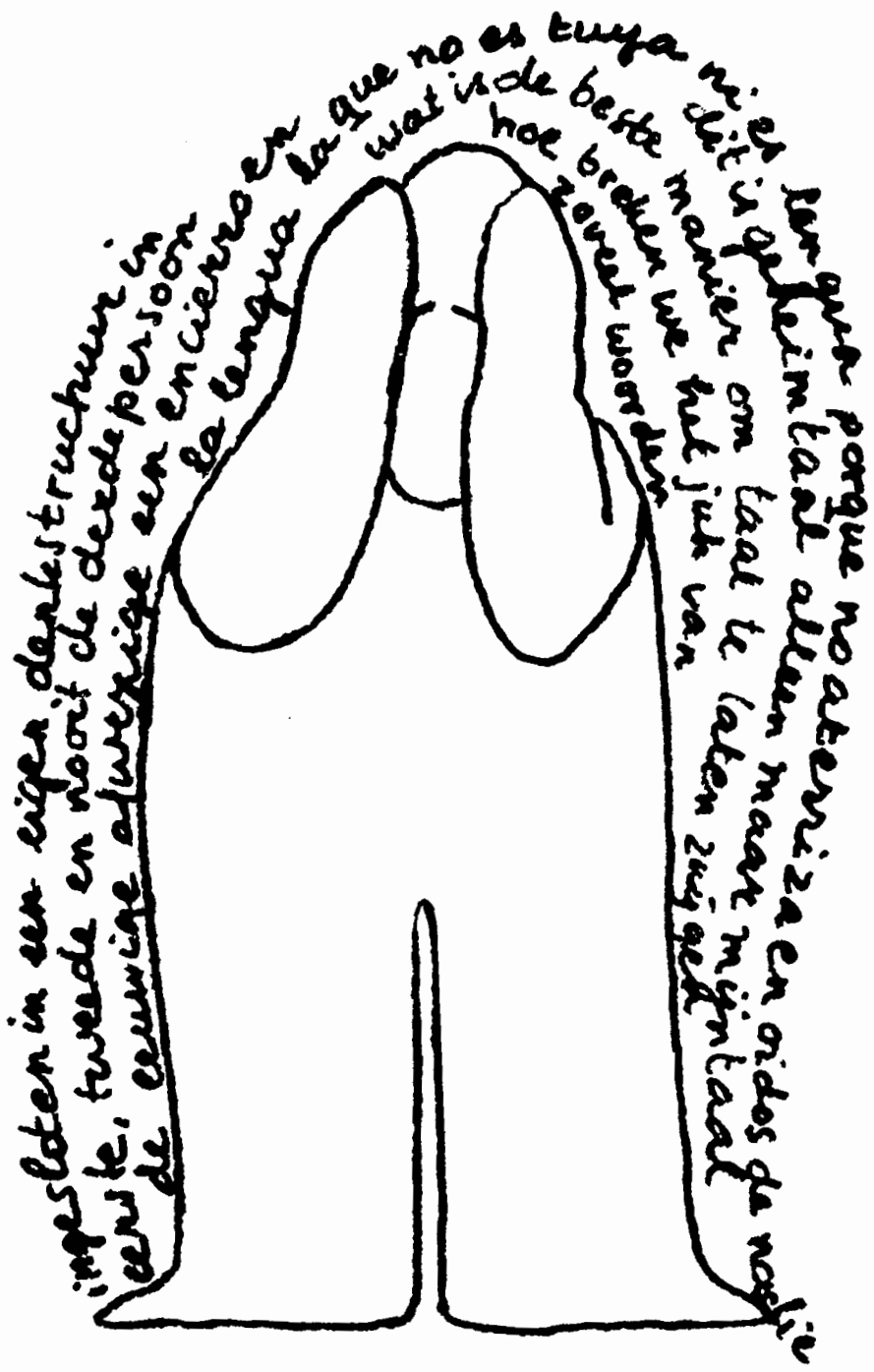


del proceso productivo; el viejo taller artesanal de grabado e imprenta de principios de siglo fue transformándose con el correr de los años en un verdadero establecimiento multigráfico. A medida que se iban operando los cambios, los empresarios dividieron las modernas instalaciones en secciones y departamentos de acuerdo con los procesos desarrollados en cada uno de ellos. En el subsuelo ubicaron los depósitos de papel, la fundición y estereotipia, el departamento eléctrico con modernas máquinas para iluminación del edificio y fuerza motriz para las maquinarias. En la planta baja situaron los escritorios, el departamento de carga y descarga de papel, máquinas impresoras, rotativas, prensas litográficas, depósitos para piedras y ponceadores, gálvano, barnizaje, engomado y perforación. El primer piso estaba destinado exclusivamente a la composición manual y mecánica, con las cajas tipográficas, los linotipos y monotipos. En el segundo piso ubicaron la sección de dibujo, los nueve laboratorios de fotografía, montaje de clichés, grabado, encuadernación y la sección de mecánica. La distribución del papel dentro del edificio fue realizada por medio de vagonetas y vías férreas. ${ }^{8}$

Esta descripción nos permite apreciar las modificaciones realizadas a lo largo de los años por los empresarios Ortega y Radaelli con el objetivo de ampliar la gama de productos, así como la calidad y los volúmenes producidos, para poder competir en el mercado de

8 Sociedad Tipográfica Bonaerense, 1857-1907, s.p.i. las artes gráficas y ubicarse en un lugar destacado del mismo. Una de las incorporaciones más significativas fue el proceso de rotofotograbado; durante años este establecimiento tuvo la exclusividad en el país sobre este "proceso de punta".?

Las publicaciones periódicas y los folletos de gtan tiraje fueron parte de la producción más característica de esta empresa: entre las primeras se destacaban Caras y Caretas, El Hogar y Mundo Argentino (desde 1911), estas dos últimas publicaciones de la editorial Haynes, que instaló talleres propios en 1918; de los segundos, el gran catálogo de propaganda de la casa Gath y Chaves. La confección de las revistas, con un corto tiempo para la producción entre número y número, la gran cantidad y alta calidad de material tipográfico y de ilustración, y el gran vo-

9 En 1921 la Compañía General de Fósforos, compradora de la firma Radaelli, describía de este modo las capacidades técnicas del establecimiento: "Con dicha adquisición, esta compañía puede abarcar todas las múltiples e importantes ramas del arte gráfico, cuya explotación había iniciado en reducida escala hace 30 años. Con la incorporación de los Talleres Radaelli a los Talleres Gráficos que ya posee en la calle California 2000 , esta compañía ofrece a su clientela un organismo dotado de todas las maquinarias y de todas las instalaciones más modernas -entre ellas la rotofotogravure- estando por lo tanto en condición de ejecutar cualquier trabajo, desde el más pequeño y modesto, hasta el más completo y artístico", en Archivo Empresarial Compañía General de Fósforos-Compañía General Fabril Financiera (en adelante AECGF-CGFF), Circulares, Sucesión Radaelli y Compañía General de Fósforos, 26 de septiembre de 1921. 
lumen de su tiraje, ${ }^{10}$ exigían, por un lado, la modernización técnica $y$, por otro, la más compleja y exacta organización del taller.

\section{LA COMPOSICIÓN DE LA FUERZA LABORAL EN UNA EMPRESA MULTIGRÁFICA}

La nueva estructura del establecimiento permitió completar la integración de los trabajadores de distintos oficios gráficos y de operarios sin habilidad ni calificación. La cifra de trabajadores empleados alcanzó los 350, según los datos ofrecidos por la prensa obrera al comentar el conflicto que tuvo lugar en Ortega y Radaelli durante quince días del mes de julio del año 1908. ${ }^{11}$ Por otro lado, si contrastamos estas cifras con las de otros talleres considerados grandes para la misma época, podemos observar que se asemejaban; por ejemplo, la Compañía Sudamericana de Billetes de Banco, que confeccionaba PBT, empleaba hacia 1907 alrededor de 400 trabajadores.

Los empresarios se alejaron cada vez más de la dirección de la producción para ocuparse de la atención de los negocios, y delegaron en una estructura muy amplia de regentes y capataces la

10 En 1914 el tiraje de cada edición de las publicaciones fue el siguiente: Caras y Caretas 115 000; El Hogar, 45 000, y Mundo Argentino 127 000, Censo, 1914, t. ix, p. 276.

${ }^{11}$ El Obrero Gráfico, año I, núm. 20, 1 de agosto de 1908 , p. 8. Cifras semejantes brindaban los periódicos La Vanguardia y La Protesta en ocasión de comentar el mismo conflicto. supervisión técnica del proceso de trabajo, lo que significó para los trabajadores una vigilancia más estrecha del trabajo y una mayor disciplina laboral. ${ }^{12}$ Para el trabajador calificado el nuevo escenario laboral del establecimiento de Ortega y Radaelli fue una experiencia de trabajo diferente, muy alejado del apacible taller artesanal, en el sentido de una imagen tradicional e inmutable, en el cual el artesano u hombre de oficio era capaz de realizar la totalidad del proceso de trabajo. ${ }^{13}$

¿De qué manera los cambios técni$\cos$ y la creciente división se tradujeron en la composición de la fuerza laboral y las calificaciones? La adecuación de un proceso artesanal a una producción más amplia mediante el uso de nuevas tecnologías y una creciente división de tareas no afectó a todos los oficios por igual. En algunos sectores hubo una permanencia de antiguas formas de trabajo y viejas jerarquías; otros, en cambio, sufrieron más las transformaciones; esto trajo cambios en las propias filas de los trabajadores calificados, necesitados de los viejos saberes, pero

12 En contraste, los propietarios de pequeños establecimientos de imprenta desempeñaban múltiples tareas: atender a la clientela, Hevar la contabilidad del negocio, comprar insumos y materias primas. También organizaban y supervisaban el trabajo del reducido número de empleados, además de trabajar junto con ellos.

13 Como ha señalado John Rule: "No es cierto que el nivel de calificación, el control sobre el proceso de trabajo ni la intensidad y la remuneración del trabajo permanezcan sin alteraciones simplemente por el hecho de que persistan los modos de producción manuales", Rule, Clase, 1990 , pp. 28-29. 
cada vez más especializados en determinadas clases de trabajos y maquinarias.

En las páginas siguientes analizaremos la composición de la mano de obra en un taller gráfico de grandes dimensiones y de mayor complejidad en el proceso de trabajo. Las cuantificaciones elaboradas a lo largo del trabajo muestran una tendencia sobre la demanda de personal y las trayectorias laborales de los trabajadores calificados en las dos primeras décadas del siglo XX. ${ }^{14}$

14 Hemos utilizado el registro de personal del Taller Heliográfico de Ortega y Radaelli y las fichas de personal de la Compañía General Fabril Financiera-Talleres Gráficos. En diciembre de 1919 el director del Departamento Nacional del Trabajo certificó los dos tomos del libro de personal del establecimiento Radaelli. Estos dos tomos tenían en total 1000 fojas, de las cuales 641 fueron completadas con datos de los empleados. A su vez, cada foja poseía una serie de ítems: nombre y apellido, lugar de nacimiento, nacionalidad, oficio o tarea realizada, fechas de ingresos y egresos, mecanismos utilizados para el ingreso, tarifa salarial (por día y mes), ascensos de categorías o pases a otras secciones. Del total de los 641 trabajadores inscritos hemos podido reconstruir los datos de 631, y algunos de ellos con ciertas dificultades. Fue imposible obtener información sobre diez registros - diferencia entre nuestra reconstrucción y los consignados oficialmente- por el mal estado de conservación que afectó siete fojas, mientras que las tres restantes fueron anuladas por la empresa.

\section{LOS TRABAJADORES DE LOS OFICIOS GRÁFICOS}

\section{Composición $^{15}$}

El total de la mano de obra registrada en esta sección, entre 1901 y 1920 , fue de 100 trabajadores. Aquí tuvo plena vigencia el sistema tradicional de oficialía: aprendices, medio oficiales y oficiales. ¿Qué significó ello? Cada una de estas categorías expresaban tanto las habilidades adquiridas por los trabajadores a lo largo de la carrera laboral hasta llegar al vértice de la pirámide jerárquica, como la clase de trabajos que podían realizar.

La integración de la nueva tecnología, ocho máquinas de composición, originó una nueva especialización: el compositor mecánico. El tradicional oficio de compositor se subdividió en tipógrafos y compositores mecánicos. A su vez, estos últimos se subdividie-

${ }^{15}$ El punto de partida del proceso en las artes gráficas comenzaba en la caja a cargo del tipógrafo o en el tecleado del texto por el linotipista. Para componer manualmente, el cajista se ubicaba ante la caja sosteniendo con la mano izquierda el componedor en el que iba colocando, de izquierda a derecha, las letras que tomaba de los cajetines en que estaban distribuidas. Una vez finalizada esta operación se retiraba del componedor y se llevaba a la galera, siguiendo en igual forma hasta alcanzar cierto número de líneas. Esta composición se ataba, apretándola bien, con un bramante, quedando lista para sacar la primera prueba. Seguidamente se realizaban las correcciones del texto, modificando el cajista los errores tipográficos en la galera, este proceso se repetía varias veces con la finalidad de asegurar un texto sin erratas listo para la impresión. Para los procesos de trabajo, véase Zimbalist, "Technology", 1979, pp. 103-126. 
ron en linotipistas y monotipistas, según la máquina en la cual se especializaron.

Los trabajadores gráficos de entonces se embarcaron en una larga lucha por establecer normas muy precisas que demarcaran las competencias de cada uno de los oficios en la composición. Además, introdujeron reglas muy detalladas que regulaban la innovación anteriormente citada. ¿Cómo se tradujo lo hasta aquí expresado en la contratación de personal?

El elevado porcentaje de oficiales se explica por la producción de impresos de alta calidad, para los cuales los dueños tuvieron que recurrir a una mano de obra calificada. El abultado número de tipógrafos da cuenta de la importancia que conservó el proceso de trabajo manual, que con la entrada de la nueva tecnología no fue relegado a una posición marginal. La creciente producción de impresos se veía frenada por el muy lento proceso manual de composición. Este problema no fue solucionado únicamente a través de la incorporación de máquinas de componer, sino también por la vía de la contratación de una numerosa mano de obra. El ingreso de tipógrafos no se detuvo por la introducción de la maquinaria; en el año veinte ingresaron a la sección de tipografía cuatro oficiales y un aprendiz tipógrafo.

Para la composición mecánica hubo un mayor porcentaje de linotipistas que de monotipistas, este dato debe interpretarse como una preferencia de los industriales gráficos por los linotipos para la producción de publicaciones periódicas, a la que se dedicaba mayoritariamente el establecimiento Radaelli.
En los talleres de gran envergadura la introducción de las máquinas de composición derivó en una más amplia división del trabajo: el operador de la máquina, a cargo de la confección del texto, y el mecánico linotipista, encargado del mantenimiento y reparación de las linotipos. Los linotipistas de las pequeñas unidades productivas realizaban el proceso de composición propiamente dicho y la limpieza del teclado, entre otras tareas. ${ }^{16}$

Los trabajadores que integraban la jerarquía de oficiales tuvieron una permanencia bastante prolongada en el taller, que se tradujo en altos niveles de regularidad en el empleo. Si bien no todos los empleados en Radaelli tuvieron una larga estancia en cada uno de los puestos de trabajo y consecuentemente una mayor certidumbre en la actividad, podemos afirmar que la mano de obra calificada tendió a una cierta estabilidad laboral y a la conservación del oficio aprendido en edad temprana. ${ }^{17}$ No era habitual que un trabaja-

${ }^{16}$ Entre los contratados, el argentino Agapito Hermida, nacido en 1890 , ingresó como mecánico de linotipos en marzo de 1919; en 1921, con la compra del establecimiento, pasó a trabajar para la Compañía General de Fósforos hasta 1930 , cuando, como la mayoría del personal, fue despedido a causa de su participación en una huelga. Reingresó en 1931 y se retiró definitivamente del taller en 1932. AECGF-CGFF, Talleres Gráficos, Registro de personal, folio núm. 406 y legajo personal núm. 1370.

17 Entre los años 1890 y 1930 la provisión de mano de obra estacional para la agricultura determinó las características y dinámica del mercado de trabajo nacional. El mercado demandaba abundante mano de obra no calificada, en permanente movilidad espacial y laboral. Los trabaja- 
dor calificado de las artes gráficas cambiase su oficio o, como sucedía a menudo con la mano de obra no calificada, deambulase por secciones y máquinas hasta encontrar un puesto laboral en el que por fin se establecía por un tiempo.

Un ejemplo de lo afirmado es la trayectoria de José Cesio, tipógrafo de nacionalidad argentina, empleado en la empresa por 18 años consecutivos (desde junio de 1900 hasta agosto de 1918). ${ }^{18}$ Otro caso ejemplificador es el fundidor monotipista Juan Loréfice, quien ingresó en noviembre de 1908 y se retiró en septiembre de 1923 . Había nacido el 5 de septiembre de 1887 en Modica, Ragusa, Italia. Ingresó al país en 1908, con 21 años de edad, y poseía estudios primarios. A pesar de no contar con información sobre su experiencia de trabajo previa, debemos suponer, por la edad en que arribó a la Argentina, que este oficial monotipista adquirió los conocimientos de compositor en su país de.origen. La ficha personal en la Compañía Fabril Financiera, último establecimiento gráfico en el que trabajó hasta 1949, nos amplía su trayectoria laboral. Según los registros, trabajó como monotipista 37 años y siete meses, distribuidos del siguiente modo: en Radaelli permane-

dores fluctuaban de las actividades rurales a las urbanas con la consiguiente falta de continuidad en las ocupaciones, esta situación atentaba contra la formación profesional de los trabajadores y tradiciones profesionales transmitidas de padres a hijos. Véase Pianetto, "Mercado", 1984, pp. 297. 307.

1.8 AECGI-CGFF, Taller heliográfico de Ortega y Radaelli, Registro de personal, folio núm. 44. ció catorce años y siete meses, luego pasó a Peuser, también como monotipista, donde trabajó alrededor de siete años. Finalmente, en el año 1932 ingresó a Fabril Financiera y permaneció como monotipista por 16 años hasta su retiro jubilatorio. 19

Por debajo de la jerarquía de oficiales, los medio oficiales eran una categoría poco significativa en términos de cantidad, y el porcentaje de aprendices cajistas era mayor que en la composición mecánica.

Cuando estudiamos a los trabajadores calificados debemos considerar el control ejercido por ellos sobre el acceso a los oficios, en tanto ese control se tradujo en la estructura de la mano de obra. El bajo porcentaje de aprendices linotipistas, por ejemplo, fue el resultado de la puesta en marcha de mecanismos restrictivos a la contratación de aprendices. Los compositores hicieron cumplir a los dueños de los talleres las regulaciones pactadas en 1906, cuyo objetivo era limitar el acceso al aprendizaje de la composición mecánica.

Según esas cláusulas, ${ }^{20}$ los aspirantes a linotipistas fueron trabajadores for-

19 AECGF-CGFF, Taller heliográfico de Ortega y Radaelli, Registro de personal, folio núm. 65 y legajo personal núm. 934 .

${ }^{20}$ La primera cláusula establecía que sólo podía emplearse un aprendiz por cada tres oficiales; la segunda reglamentaba la prioridad de los antiguos cajistas para la formación de linotipistas. Otras disposiciones estipulaban muy detalladamente el aprendizaje: horarios en que podía realizarse, su condición de trabajo no remunerado, y que la producción hecha durante el periodo de práctica no debía utilizarse en los trabajos en marcha en el taller. Después de uno o dos meses de práctica, y 


\section{Cuadro 1. Composición. Estructura de la mano de obra}

Oficios

$\begin{array}{lcccc} & \text { Oficiales } & \text { Medio oficiales } & \text { Aprendices } & \text { Ayudantes máquinas } \\ \text { Tipógrafos } & 44 & 4 & 11 & \\ \text { Linotipistas } & 27 & & 4 & \\ \text { Monotipistas } & 4 & & 1 & 2 \\ \text { Mecánicos linotipistas } & 2 & & 1 & 2\end{array}$

FUENTE: AECGF-CGF, Registro de personal del Taller heliográfico de Ortega y Radaelli.

mados en la tipografía. Tal vez por ello, en los convenios de tarifas salariales para composición mecánica no figuraron los salarios de los aprendices, como en el resto los oficios. Sin embargo, los cuatro aprendices de Ortega y Radaelli tuvieron estipulada una tarifa diaria y mensual, similar a la asignada en los otros oficios calificados, aunque nunca concretaron un ascenso en su carrera laboral dentro del taller.

En cuanto a la nacionalidad, en el conjunto de los trabajadores de la sección de composición, los argentinos llegaron a representar 47\%; el segundo grupo corresponde a los italianos, con $24 \%$, en tercer lugar los españoles, con $19 \%$, y los uruguayos con $6 \%$. El resto eran trabajadores de las siguientes nacionalidades: brasileños, belgas, paraguayos y franceses, cada uno de ellos con $1 \%$ del total.

cuando alcanzaban una producción de 3000 letras por hora, los nuevos linotipistas comenzaban a cobrar el salario de tarifa establecido para el oficio. El convenio fue publicado en el Boletín de la Unión Industrial Argentina (en adelante BUIA), octubre-noviembre de 1906, pp. 38-50.
Por la índole del oficio, que requería trabajadores alfabetizados y con un manejo del idioma castellano, en la relación nacionalidad-idioma la presencia más nutrida, cercana a las tres cuartas partes del total de la mano de obra, correspondió a aquellos trabajadores que por país de origen dominaron fluidamente el castellano. Sin embargo, nos llamó la atención la presencia de un núcleo de trabajadores italianos en la sala de composición. ${ }^{21}$

21 Como en el registro de personal no constaban el año de ingreso a Argentina ni la experiencia laboral previa, nos es imposible comprender si la adquisición del idioma y el aprendizaje del oficio lo realizaron en este país por haber emigrado de la península a una edad muy temprana. Sean Wilentez destaca que ya para 1855 una gran parte de los compositores de la ciudad de Nueva York debían estar alfabetizados en el inglés. Ese requerimiento alejó de las salas de composición a los alemanes y a los irlandeses pobres. Alrededor de la mitad de los compositores eran nativos; mientras una tercera parte de los inmigrantes eran de Inglaterra, Escocia y Gales. Véase Wilentez, Chants, 1984, pp. 129-132. 
Cuadro 2. Grabado. Estructura de la mano de obra

Oficios

Grabador

Grabador especializado

Montador de grabado

Totales

\section{Oficiales}

14
3
1
18
Categorias

Medio oficiales

3

4

4

FUENTE: AECGF-CGFF, Registro de personal del Taller heliográfico de Ortega y Radaelli.

Cuadro 3. Fotograbado. Estructura de la mano de obra

Oficios

Categorías

Oficiales

11

3

14

3

Medio of iciales

Aprendices

Fotograbador

Fotograbador especializado

Totales
1

1

FUENTE: AECGF-CGFF, Registro de personal del Taller heliográfico de Ortega y Radaelli.

\section{Grabado, fotograbado y fotografía 22}

Estos procesos de trabajo experimentaron importantes innovaciones técnicas; sin embargo, requirieron una mano de obra de alta calidad. Las categorías que quedaron registradas en el libro de personal muestran la vigencia de las jerarquías y los oficiales como miembros de profesiones, con cualificaciones específicas y con un "sello aristocrático" con respecto a los demás oficios gráficos.

${ }^{22}$ Los procesos de grabado y fotograbado producen placas metálicas en relieve con gráficos, dibujos, fotografías y, en general, todo material que no puede componerse en tipo, y requiere oficios con elevada especialización. El relieve de las pla-
En el grabado pudimos constatar 25 trabajadores, y en la sección de fotograbado, un total de quince trabajadores de oficios. La jerarquía máxima de los oficios de estas secciones eran las

cas se obtiene mediante "mordidos" o ataques con ácidos; las partes de la placa que no sufren el ataque quedan elevadas sobre el resto del material y forman la imagen que se ha de imprimir. La primera parte del trabajo consiste en generar la imagen sobre la placa cubriendo el metal y protegiéndolo del ataque del ácido en las zonas que deben quedar elevadas. Para ello puede partirse de trazados con tinta grasa sobre papel de transporte o sobre piedra litográfica pasados a papel de transporte; estas imágenes se calcan sobre una placa de cinc utilizando una prensa mecánica, se retocan y, después de varios procesos para reforzar la protección del metal en los trazos de la ima- 
Cuadro 4. Fotografía. Estructura de la mano de obra

Oficios

Fotógrafo

Fotógrafo especialista

Totales
Categorías

Oficiales Medio oficiales

3

2

5
Aprendices

FUENTE: AECGF-CGFF, Registro de personal del Taller heliográfico de Ortega y Radaelli.

más numerosas. Los medio oficiales y aprendices de grabado ingresaron en el último tiempo de existencia del taller, entre 1918 y 1920.

Durante los años comprendidos en este estudio, en la sección de fotografía quedaron asentados un total de siete personas.

En el fotograbado no hubo una degradación del aprendizaje, como señalamos para la encuadernación. El aprendiz de la sección de fotograbado, Ângel Osés, ingresó al taller en 1915 , permaneció alrededor de cinco años,

gen, la placa queda lista para los baños ácidos. Los "mordidos" son varios (previo, medio, redondo y final) y luego la placa puede retocarse mecánicamente. Una vez finalizada, se monta sobre un pie de madera y se le da la altura de los tipos. En el fotograbado, la transferencia de la imagen a la placa se realiza mediante técnicas fotográficas. Se parte de un negativo realizado en una placa de vidrio con una emulsión fotográfica preparada con colodión y nitrato de plata. Una vez revelado el negativo, se recubre la placa con betún de judea disuelto en bencina y se coloca encima el negativo, realizándose mediante luz solar una copia positiva sobre la placa. Viene después un primer grabado con ácido, y luego una serie de etapas de deposición de tinta protectora y mordidos de mayor profundidad, al igual que en el caso del grabado. durante su prolongada estancia realizó el aprendizaje al viejo estilo: al lado de los hombres del oficio y observando todos los secretos del proceso laboral. Cuando se retiró del taller en el año veinte había ascendido a oficial fotograbador.

\section{Litografía ${ }^{23}$}

Otro oficio resguardado de los grandes cambios fue el de litografía. Si bien existió una mecanización parcial del proceso laboral; sin embargo, fue imposible contratar "obreros incompletos" para realizar operaciones que requerían gran precisión. Por tanto, la

${ }^{23}$ A diferencia del grabado, en la litografía la imagen a imprimir no está en relieve. lá diferencia entre las zonas que se imprimen y aquellas que no, se basa en la falta de adhetencia entre el agua y el aceite. Se parte de una piedra a la que se debe cortar, pulir con piedra pómez ("apomazar") y dar un acabado fino. Se dibuja con lápiz graso o tinta litográfica. Las zonas dibujadas presentan adherencia a la tinta de base grasil, mientras que el resto de la superficie la rechaza. Una vez terminado el dibujo original, se generan copias sobre otras piedras, que se llaman "reportes". 
Cuadro 5. Litografía. Estructura de la mano de obra

Oficios

Prensista/transportista y máq. litógrafo

Pomaceador

Ponepliego

Sacapliego

Totales
Oficiales

5

15

26
Categorias

Medio oficiales

2

14

43

72

FUENTE: AECGF-CGFF, Registro de personal del Taller heliográfico de Ortega y Radaelli.

calificación no sufrió una degradación, y el aprendizaje del oficio requirió un prolongado periodo de tiempo. El personal inscrito para esta sección fue de 84 hombres. Tanto el transporte del trabajo y el grabado de la piedra, que dependía por completo de la acción de sustancias químicas (ácidos), como la impresión propiamente dicha, eran operaciones realizadas por personal altamente capacitado. En la litografía, el viejo mundo jerarquizado del taller tenía plena vigencia; prensistas-transportistas y maquinistas litógrafos ocupaban el vértice de la jerarquía, un porcentaje muy reducido del total. En contraste con la impresión tipográfica, aquí no encontramos la estratificación de maquinistas de primera o de segun-

El primer reporte, o "reporte matriz", se realiza tirando una prueba del original y transfiriendo el dibujo a otra piedra. A partir de éste, se generan los reportes para impresión simultánea de una cantidad de copias en cada estampación. Para ello se tiran copias y disponen sobre un pliego del tamaño del papel a imprimir, se transfiere a una piedra litográfica mediante la prensa y se fija químicamente. da. Medio oficial transportista y maquinista, junto a los aprendices de las mismas profesiones, estaban interesados por completar la carrera laboral y alcanzar ese vértice de la profesión. Los pomaceadores tenían a su cargo la ejecución de las operaciones de nivelado, graneado y corte de las piedras para los diversos procedimientos litográficos.

A continuación estaban los ponepliegos; estos trabajadores realizaban la misma tarea de "alimentar" que sus pares de tipografía, pero con una mayor exigencia en cuanto a la precisión. Los ponepliegos de litografía tuvieron la posibilidad de realizar una carrera laboral a partir de la negociación del convenio en 1919. De acuerdo con las nuevas normas, estos trabajadores, luego de una trayectoria de tres años por los escalones inferiores del oficio, estaban capacitados para iniciar el tránsito por las sucesivas categorías de maquinista. De hecho, esta situación se convirtió en un estímulo para los trabajadores, y una de las razones para permanecer durante más tiempo en el puesto, con vistas a realizar una carrera laboral digna y bien remunerada. 
Cuadro 6. Estereotipia. Estructura de la mano de obra

Oficios

\begin{tabular}{cccc}
\multicolumn{4}{c}{ Categorias } \\
Oficiales & Medio oficiales & Aprendices & Ayudantes \\
8 & 1 & 1 & 2 \\
8 & 1 & 1 & 2
\end{tabular}

FUeNTE: AECGF-CGF, Registro de personal del Taller heliográfico de Ortega y Radaelli.

En contraposición, los aprendices sacapliegos y sacapliegos propiamente dichos realizaban la misma tarea que la descrita para sus pares de la sección de impresión tipográfica: retirar la hoja impresa de la máquina, para lo cual no era necesario realizar adiestramiento. La posición laboral de estos trabajadores era muy semejante a la de los aprendices encuadernadores, porque realizaban tareas concretas en el proceso laboral y la mayoría de ellos eran trabajadores menores de edad, con una permanencia muy corta en el taller. La mano de obra sin calificación de la sección impresión litográfica y encuadernación era homogénea e intercambiable entre ambos departamentos. Un ejemplo de ello fue el caso de Luis Alguerralde, que pasó de aprendiz encuadernador a sacapliegos de litografía. A partir de la información sobre fecha de nacimiento $y$ año de entrada al taller, pudimos obtener la edad a la que ingresaban los sacapliegos. La incorporación de la inmensa mayoría fue a los quince o 16 años de edad. En estos puestos hubo un nivel de rotación del personal muy grande. "Jóvenes díscolos" para los patrones gráficos, los mismos reclamaron un mayor disciplinamiento de los ponepliegos-sacapliegos. Los patrones de imprentas exigieron a los oficiales maquinistas la responsabilidad en la labor de disciplinar personal. En otros establecimientos ingresaron mujeres como sacapliegos, una estrategia igual a la seguida en encuadernación.

\section{Estereotipia ${ }^{24}$}

Los talleres que realizaban grandes tirajes y habían incorporado rotativas necesitaron organizar una sección de estereotipia. Este proceso fue considerado siempre muy insalubre por el empleo de bencinas, aceites, metal líquido compuesto de plomo y antimonio,

24 La estereotipia sirve para generar varias placas de impresión a partir de un único original de composición. Una vez generadas las copias, puede reciclarse el material utilizado en el original. Este sistema "permitía que en cualquier momento se pudiese hacer una nueva impresión con una plancha sólida y de una sola pieza, la cual era fundida utilizando un molde de cartón piedra o de sustancia similar, preparado con la 'forma' original. Las planchas metálicas de estereotipia para rotativas adoptaban la forma curva para poder montarlas en el cilindro, y en ellas se copiaba la forma original de la página completa de un periódico o revista", en Derry y Williams, Historia, 1977 , t. 3, pp. 953-954. 
Cuadro 7. Impresión. Estructura de la mano de obra

Oficios

Porcentaje por categorías

Oficiales

Medio of ficiales

Aprendices

Asistentes

Maquinista impresor

3

Maquinista de segunda

Minervista

6

1

Ponepliego

Sacapliego

Totales

FUENTE: AECGF-CGFF, Registro de personal del Taller heliográfico de Ortega y Radaelli.

además del intenso calor de calderas y prensas utilizadas en los sucesivos pasos para la confección de la plancha de estereotipia. Los trabajadores de esta sección estaban encuadrados dentro de las categorías habituales de los oficios tradicionales. En la sección de estereotipia fueron registrados doce trabajadores.

\section{Impresión 25}

Los maquinistas de impresión tipográfica intervenían en el proceso de impresión en sentido estricto; eran un sector de trabajadores calificados que mantuvo esa posición a pesar de la continua incorporación de maquinaria

${ }^{25}$ El proceso de impresión tiene varias etapas. La primera de ellas es la "preparación", que consiste en colocar la placa de impresión en la máquina, trabarla y asegurar que apoye sobre la superficie de impresión en forma pareja y con la fuerza adecuada. Ésta es un proceso muy complejo, especialmente en la prensa plana. Para nivelar la placa es necesario, a menudo, colocar suple- muy moderna. La explicación es en parte tecnológica. No todas las operaciones fueron mecanizadas; algunas, como la mezcla de tintas para obtener las tonalidades de cada trabajo, formaban parte de los saberes y especialidad. El maquinista era responsable de las llaves de las máquinas y del trabajo del personal a su cargo, compuesto por aprendices, ayudantes, ponepliegos y peones de máquinas. El oficio era una realidad, y los maquinistas mantenían

mentos de papel en determinadas zonas. El segundo paso es preparar la mezcla de tinta y agua y agregar secadores o diluyentes en la proporción adecuada para cada tipo de trabajo. Una vez preparada la tinta, debe asegurarse su distribución pareja sobre la superficie de los rodillos de entintado. Para ello la máquina dispone de una serie - de llaves que es necesario ubicar y regular adecuadamente. Una vez puesta en marcha la impresión, estos parámetros deben controlarse y regularse continuamente. Al mismo tiempo, el operador debe vigilar y ajustar los márgenes de la impresión. Si se imprime a varios colores, debe vigilar el registro de los mismos para que los colores no aparezcan corridos; esto requiere precisas y cuidadosas manipulaciones. 
SECUENCIE

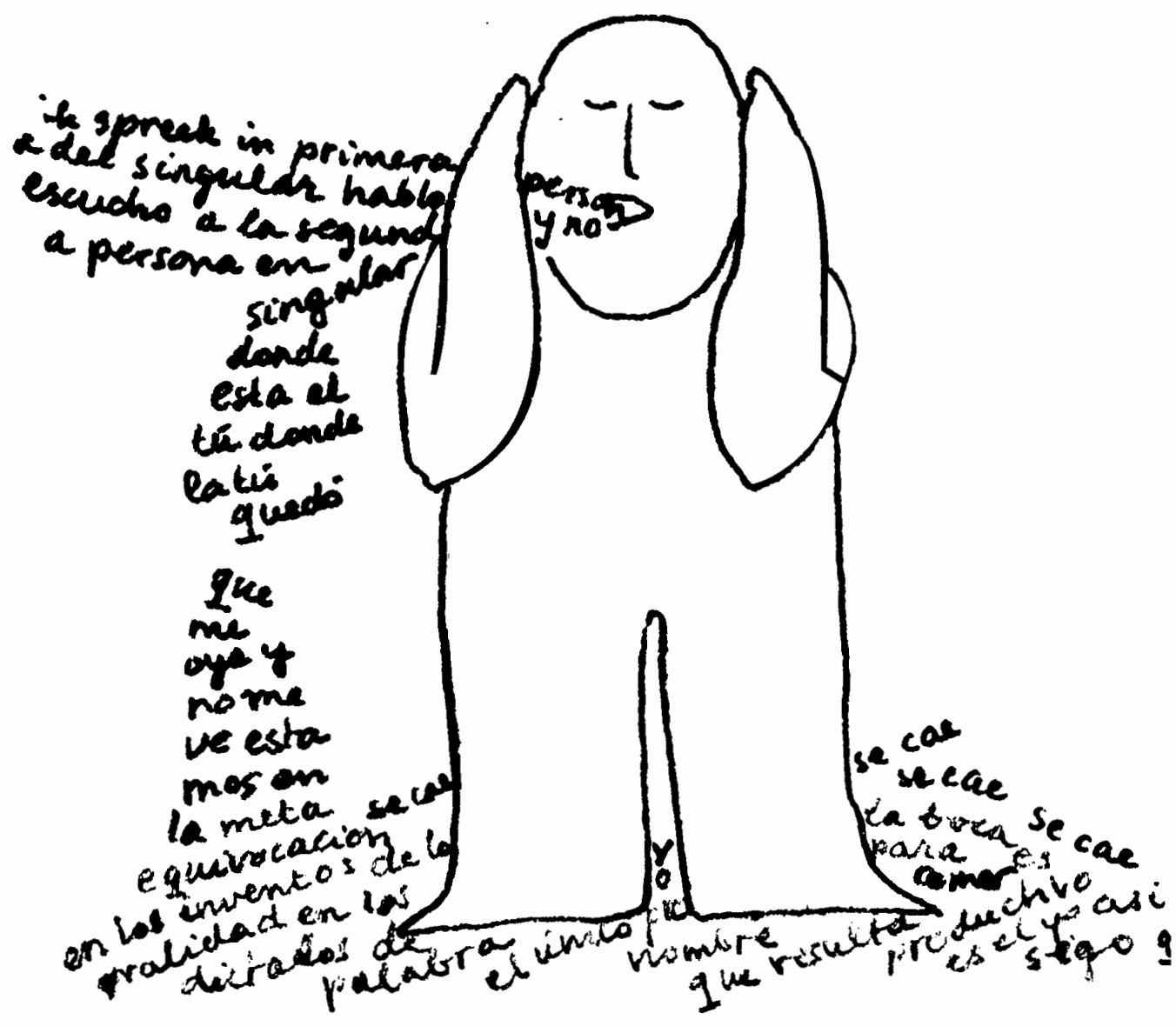


el sistema de aprendizaje y el de oficialía en distintos grados. Uno de los cambios en la fuerza laboral en relación con la incorporación de rotativas en la sala de impresión, fue la puesta en vigencia de la categoría "maquinista de segunda".

Como grupo, los trabajadores de la sala de impresión tuvieron la suficiente fuerza como para hacer respetar las distintas categorías por las que debía transitar un individuo para llegar a ser oficial. Fue difícil para los individuos que iniciaban su carrera laboral alcanzar las jerarquías máximas del oficio. La situación generó tensión en torno a la movilidad vertical entre las diversas categorías de la impresión tipográfica. René Stordeur comentó el hecho así:

Entonces se quería aprender el oficio. El de abajo quería ser oficial, el oficial no siempre se prestaba a que el de abajo llegara a tener los conocimientos que él tenía; temía la competencia; temía que ese hombre; que ese hombre que estaba ganando la mitad de lo que ganaba él, en cualquier momento se prestara a reemplazarlo. ${ }^{26}$

En el libro de personal fueron registrados 78 trabajadores en la sección máquinas tipográficas. Junto a los maquinistas impresores y la nueva categoría de maquinistas de segunda, y bajo su mando en el momento de la impresión, estaba el asistente de máquina. Los minervistas eran impresores que

26 Entrevista al dirigente gráfico René Stordeur realizada por Luis Alberto Romero para el Proyecto de Historia Oral, Instituto Torcuato Di Tella, 1970-1971, pp. 160-161. operaban una prensa de tamaño pequeño denominada minerva, utilizada en la producción de trabajos comerciales, tarjetería, papel carta, etc. Los ponepliegos de impresión tipográfica estaban encargados de la tarea de alimentar con papel las prensas planas. En Ortega y Radaelli esta operación fue mecánica luego de la incorporación de prensas con ponepliegos automáticos, sin embargo la coexistencia de distintas tecnologías durante un largo tiempo hizo que el "ponepliego" no desapareciera. Jóvenes, la mano de obra más barata, desempeñaban la tarea de "colocar pliegos a la aguja o la escuadra". A ellos se sumaban un grupo de aprendices sacapliegos que realizaban la rutinaria tarea de sacar la hoja ya impresa de las prensas que no tenían mecanizada la operación, su situación estuvo emparentada con la de los aprendices encuadernadores.

\section{Encuadernación ${ }^{27}$}

A fines del siglo XIX y principios del $\mathrm{XX}$ los encuadernadores sufrieron las presiones de los empresarios por meca-

27 El punto de partida de la fase de encuadernación es el plegado, generalmente hecho a máquina para las publicaciones periódicas y los trabajos comerciales. Continúa con el alzado de los pliegos y la colocación de las láminas, si éstas se han impreso por separado. Luego se realiza el cosido de los pliegos, a mano (con hilo) o a mácuina (con ganchos de alambre). El cosido a mano da mayor solidez, pero para las revistas o publicaciones comerciales de duración pasajera se realiza a máquina. Terminadas las operaciones de cosido, encolado y colocación de las tapas, se procede al recorte mediante la guillotina. 
Cuadro 8. Encuadernación. Estructura de la mano de obra

\begin{tabular}{lrcc} 
Oficios & \multicolumn{3}{c}{ Porcentaje por categorias } \\
& Oficiales & Medio oficiales & Aprendices y aprendices adelantados \\
Encuadernador & 47.5 & 2 & 44 \\
Doblador & 3.0 & & \\
Cortador & 2.0 & & \\
Recotista & 1.0 & & 44 \\
Numerador & 0.5 & 2 & \\
$\quad$ Totales & 54.0 & 2 &
\end{tabular}

Fuente: AECGF-CGFF, Registro de personal del Taller heliográfico de Ortega y Radaelli.

nizar y subdividir el proceso de trabajo. El objetivo de éstos era bajar los costos mediante el ingreso de trabajadores semicalificados a los cuales se les pagaban salarios inferiores a los que ganaban los hombres con larga trayectoria en el oficio.

Las transformaciones produjeron modificaciones en la composición de la mano de obra, una de ellas fue el ingreso de las mujeres y los niños a la sala de encuadernación. La estrategia de ampliar la cantidad de trabajos que pudieran hacer las mujeres fue adoptada en los siguientes talleres: Peuser, Kraft y la Compañía Sudamericana de Billetes de Banco. ${ }^{28}$

Los empresarios Ortega y Radaelli optaron por la contratación de jóvenes como aprendices, quienes realizaban tareas concretas durante un periodo muy corto de permanencia en el taller.

En esta sección han quedado registrados 171 trabajadores. Entre el personal de encuadernación hubo oficiales

\footnotetext{
${ }^{28}$ Para una ampliación del tema véase, Badoza, "Ingreso", 1994, pp. 290-300.
}

que fueron anotados con sus correspondientes especializaciones; algunas, como marmoladores y doradores, no pudieron ser verificadas aunque estaban incluidas en los convenios de tarifas. En la encuadernación, la nueva situación de mecanización, división del trabajo y mayor ritmo laboral incrementó la demanda de oficiales, aunque con características diferentes a los que pertenecieron a los núcleos más tradicionales del oficio y que no estaban inmersos en el mundo de la competencia capitalista.

Según el testimonio del delegado obrero ante la comisión mixta gráfica, los encuadernadores del establecimiento de Ortega y Radaelli trabajaban "por el sistema llamado Taylor, que no se practica en ningún otro taller del país", con gran rapidez y automatismo. Los cambios en marcha tendieron a la búsqueda de mayor eficiencia de la mano de obra contratada mediante el pago de un salario según rendimiento o productividad de cada trabajador. En consecuencia, estos trabajadores quedaron al margen de la aplicación de la tarifa estándar. 
A pesar de los cambios, los oficiales mantuvieron la estabilidad en los puestos de trabajo. Hemos constatado, en los casos en que fueron anotadas las fechas de egreso, una permanencia en el puesto de trabajo entre dos años como mínimo y catorce o quince años como máximo; la franja más numerosa está entre los cuatro y los seis años.

Esta visión, obtenida a partir del registro de personal, es semejante a la brindada por el delegado obrero Argibay en la Comisión Mixta Gráfica en 1915. Este testigo también destacaba que los encuadernadores "viejos" de Ortega y Radaelli tenían una antigüedad de tres, cuatro, cinco y hasta diez y doce años en el taller. Juan Fasano nació el 28 de noviembre de 1878 en Solopaca, provincia de Benevento, Italia. Arribó a Argentina en el año 1898, por entonces tenía 20 años de edad y posiblemente había adquirido en Italia el oficio de encuadernador-cortador. Después de vivir seis años en este país, el 22 de enero de 1904 alcanzó un puesto en la sección de encuadernación en Ortega y Radaelli, donde permaneció hasta el 25 de septiembre de 1921. A partir de esa fecha trabajó en la Compañía Fabril Financiera hasta jubilarse en diciembre de 1948. Durante 44 años de su vida trabajó en la sección encuadernación como cortador a guillotina. ${ }^{29}$

La diferencia entre aprendiz y aprendiz adelantado no residía en sus conocimientos y aptitudes técnicas, sino únicamente en las tareas que desempe-

29 AECGF-CGFF, Taller heliográfico de Ortega y Radaelli, Registro de personal, folio núm. 125 y legajo personal núm. 316. ñaban; ocupaban el escalón inferior del oficio y la edad promedio de ingreso era de quince años. La mayoría de estos jóvenes trabajaron durante un tiempo que no excedió los cuatro o cinco meses, unos pocos alcanzaron el año de trabajo y sólo dos llegaron a estar cuatro años. El empleo temporario, las tareas simples y rutinarias, degradaron el contenido de la categoría de aprendiz; se había cortado la conexión entre carrera laboral y puesto de trabajo, situación que no observamos con tanta claridad en los otros oficios. La reestructuración del trabajo derivó, en el caso de los aprendices y aprendices adelantados, en la imposibilidad de una carrera laboral en el oficio de encuadernador.

\section{OfICIOS VARIOS Y PEONES}

Un establecimiento de la envergadura de Ortega y Radaelli, en el cual se desarrollaban todos los procesos de trabajo de las artes gráficas, debió contar necesariamente con un número considerable de trabajadores calificados de los distintos oficios y otros sin calificación.

Oficinistas, carpinteros, albañiles, fogoneros, mecánicos, electricistas, porteros, carrero, etc., unos 40 hombres, formaron parte en distintos momentos del periodo en estudio de lo que hemos denominado "oficios varios".

Comenzaremos por los oficinistas. Estos trabajadores de cuello blanco fueron creciendo en número una vez instaladas oficinas de sociedades anónimas o empresas de relativo tamaño. En nuestro caso, $25 \%$ del total de los trabajadores que denominamos de oficios 
varios, fueron registrados como "empleados de escritorio" y poseían diversos grados de instrucción. Sus tareas estaban relacionadas con la contabilidad y el resto de las tareas administrativas del taller. Los carpinteros (32\%), albañiles (7\%), electricistas (12\%), mecánicos $(5 \%)$ y fraguador $(2 \%)$ eran trabajadores calificados y estaban encargados del funcionamiento y mantenimiento del establecimiento. Porteros y serenos $(12 \%)$ realizaban la vigilancia en las puertas de cada una de las secciones y los accesos al establecimiento; eran, por lo general, hombres de confianza de los empresarios, dadas las características propias de la tarea. A través de los hombres de vigilancia la dirección de la empresa tendió, en primer término, a mantener un control estricto sobre la presencia de personal ajeno al taller, y en segundo, a un disciplinamiento de los trabajadores en el uśo del tiempo para el trabajo productivo, fundamentalmente porque esa presencia coartó la libertad de los operarios de transitar por las diversas secciones. La presencia de la vigilancia era también un modo de disuadir a los trabajadores de "introducir o retirar" elementos del establecimiento, porque en cualquier momento podían requisar las pertenencias del operario.

Sobre un total de 40 trabajadores, que agrupamos bajo la denominación oficios varios, contamos con la nacionalidad de 38 de ellos; $70 \%$ era de origen español o italiano; $22 \%$ de argentinos y $2 \%$ de rusos; formaron parte de los puestos de escritorio mejor remunerados. En los oficios varios predominaron los trabajadores de origen extranjero, aunque encontramos una gran dificultad para establecer una identificación directa entre grupo étnico y profesiones. ${ }^{30}$ En cuanto a la permanencia en los puestos laborales, los empleados de los oficios varios trabajaron durante extensos periodos, al igual que la mano de obra calificada de los oficios gráficos. Algunos alcanzaron 20 años de trabajo, como el albañil José Farré, oriundo de Arreal, Tarragona, quien ingresó en el año 1900 y se retiró en $1920,{ }^{31}$ una situación que contrastaba con los hombres de la rama de la construcción, compelidos a cambiar de obra y patrón constantemente. En la sección escritorio encontramos empleados de las jerarquías superiores con 16 , trece y once años de antigüedad en sus cargos. Entre los trabajadores de vigilancia, Luis dell'Oro trabajó durante doce años como portero de la sección litografía.

Los peones eran trabajadores no ligados a ningún oficio en particular y se encargaban de las tareas auxiliares. Estos obreros, de los cuales quedaron registrados aproximadamente 67 hombres, estaban destinados a la realización de trabajos generales del establecimiento; $18 \%$ de ese total fue registrado bajo la denominación de peones y ayudantes, mientras que $19 \%$ formó parte de la mano de obra para tareas auxiliares en las distintas secciones, ya

${ }^{30} \mathrm{El}$ caso más claro lo tuvimos con los albañiles, un oficio tradicionalmente ligado a los italianos, sin embargo, no pudimos constatar esa situación en nuestro estudio porque de los cuatro albañiles registrados, tres etan españoles y sólo uno de origen italiano.

31. AECGF-CGFF, Taller heliográfico de Ortega y Radaelli, Registro de personal, folio núm. 23. 
sea como peones de encuadernación, estereotipia, fotograbado, fotografía, grabado o taller mecánico. En la impresión, los trabajadores fueron registrados como peones de imprenta (6\%) y de máquina (24\%), una distinción que, en el segundo de los casos, hacía referencia al lugar ocupado en las tareas rutinarias y pesadas del proceso de preparación y posterior de la impresión. Por ejemplo, Antonio López arribó al país desde España en 1906; al año siguiente entró como peón de máquinas de la sección impresión tipográfica y continuó en similar posición laboral durante más de 27 años en Radaelli y Fabril Financiera. ${ }^{32}$

La sección depósito de papel, $21 \%$ del total, estaba compuesta exclusivamente por peones que realizaban las tareas de acarreo y almacenaje del papel. La presencia de peones de patio y limpieza (10\%) completaba la creciente plantilla de trabajadores sin calificación. Italianos y españoles eran mayoría entre los peones, en cuanto a los primeros, el total de trabajadores registrados con esa nacionalidad alcanzó $43 \%$, mientras que los españoles sumaron cerca de $34 \%$, los argentinos estaban en minoría, solamente $10 \%$, uruguayos y brasileños constituyeron el $3 \%$ y portugueses (3\%), una nacionalidad casi ausente en los oficios calificados. Si tomamos en cuenta los datos de ciudad y provincia de procedencia brindados por el registro de personal, podemos observar que la mayoría de los italianos eran originarios del sur

32 AECGF-CGFF, Taller heliográfico de Ortega y Radaelli, Registro de personal, folio núm. 240 y legajo personal núm. 79 . de la península itálica, y los españoles de la región gallega, es decir, que en el caso de los peones del establecimiento de Ortega y Radaelli se reprodujeron los mismos patrones de procedencia de la mano de obra no calificada que se encuentran en otras ramas productivas.

Los patrones y los trabajadores calificados esperaban que los peones desarrollaran las tareas más pesadas, con preponderancia del empleo de fuerza física. La situación anteriormente descrita tuvo consecuencias para los peones, porque en un mundo del trabajo con extrema valoración de la destreza mental, los trabajadores no calificados ocuparon el escalón laboral inferior en las artes gráficas. La demarcación entre trabajadores calificados y no calificados pasaba por la pertenencia o no al mundo de los alfabetizados, de los oficios y la posibilidad de acceder a la carrera laboral.

Aun cuando las demarcaciones fueron fuertes no significaron un cierre total a las posibilidades de ascenso. Un ejemplo de ello fue la carrera laboral de Serafín Fernández, un pontevedrino; nacido en 1886, ingresó como peón de máquinas planas en la sección de tipografía de Radaelli en 1909 y continuó en el mismo puesto hasta 1921. Con posterioridad a 1921, pasó a la Compañía Gral. de Fósforos como peón de máquinas de rotograbado (rotofotogravure). En la huelga de 1930 de Fabril Financiera fue dejado cesante, a los pocos meses reingresó pero como maquinista. ${ }^{33}$ Tal vez la falta de personal

3.3 AECGF-CGFF, Taller heliográfico de Ortega y Radaelli, Registro de personal, folio núm. 231 y legajo personal núm. 547. 
como producto de los despidos y su larga experiencia en las máquinas permitieron el ascenso laboral de peón a maquinista. Un ascenso a base de méritos, más que al cumplimiento de un aprendizaje formal del oficio.

\section{REGENTES, JEFES Y CAPATACES}

El estudio del registro de personal dio cuenta de la presencia de un importante cuerpo de dirección y supervisión en el taller. Una empresa de la magnitud de Ortega y Radaelli necesitó de esos cuadros superiores e intermedios, a quienes los empresarios delegaron la organización y control del proceso productivo. 34

Más de las tres cuartas partes fueron extranjeros, tanto este personal como el nativo tuvo un origen urbano. La mayoría había nacido en las ciudades capitales, o en destacados centros urbanos (Turín, Milán, Barcelona, Bucarest, Buenos Aires, Montevideo) de las regiones más desarrolladas de sus respectivos países de procedencia.

En el vértice de la cúspide jerárquica estaban el director técnico y el jefe de administración, y por debajo el regente general de noche, de litografía y tipografía. Comprobamos la existencia de un jefe de grabado, un encargado de tricromía, un capataz de impresión tipográfica, otros en composición, encuadernación, fotografía, dibujo, estereotipia, depósito de papel y carpintería. Para ciertas secciones fueron creados

${ }^{34}$ Para el tema véase Duarte, "Mayordomos", 1989, pp. 3-20, y Molina, "Reforma", 1996-1997, pp. $135-154$. más cargos de capataces con el objetivo de ejercer un control muy directo y detallado sobre los trabajadores. Esta iniciativa empresarial surgió posiblemente a partir del crecimiento del personal contratado y la necesidad de asegurar una disciplina del ritmo laboral con el propósito de alcanzar una mayor producción y una buena calidad de la misma. En la encuadernación constatamos la existencia de capataces de segunda y tercera, mientras que en la composición e impresión tipográfica quedaron registrados capataces de segunda, y el mismo cargo en la sección de litografía.

Parte del personal superior e intermedio fue contratado directamente para el cargo de responsabilidad, otros fueron reclutados dentro del propio personal de la empresa. Paolo Paoppi había realizado su formación en el oficio de impresor en Milán. En esa ciudad estuvo trabajando durante años como maquinista impresor del conocido diario Corriere della Sera. Seguramente sus antecedentes laborales en el extranjero, así como un año de trabajo en la Compañía General de Fósforos fueron suficientes para ingresar en 1912 como regente de noche al establecimiento de Ortega y Radaelli. Posteriormente fue contratado como director de la editorial Haynes y finalmente fue director general del taller de artes gráficas de Fabril Financiera. 35 El francés Camilo Dablanc ingresó como

35 AECGF-CGFF, Taller heliográfico de Ortega y Radaelli, Registro de personal, folio núm. 217. Entrevista realizada a Ricardo Paoppi por Silvia Badoza y Graciela Montes el 23 de noviembre de 1995 en el establecimiento litográfico fundado 
tipógrafo y ascendió a segundo capataz de tipografía. Juan Baquera de encuadernador ascendió a tercer capataz de esa sección.

Los hombres que ocuparon las jerarquías de supervisión del taller, ya sea por ascenso dentro del mismo o contratados para el cargo, tuvieron en común el haber salido de las filas de los propios oficios gráficos. Los capataces de menor jerarquía desarrollaron, paralelamente a la tarea de dirección, trabajos concretos de producción; esta doble función contribuyó a la existencia de límites difusos entre trabajadores y algunos puestos de dirección.

Los regentes, jefes, encargados y capataces gozaron de estabilidad en sus cargos. Esa estabilidad estuvo garantizada, en parte, por la pericia y conocimientos obtenidos a lo largo del tiempo $y$, en parte, por la confianza depositada por los dueños en los hombres que estaban al frente de las secciones del establecimiento. El caso de Francisco Pujol, jefe de grabado, es ejemplificador de esta estabilidad. Este barcelonés trabajó 28 años ininterrumpidos, desde que ingresó en 1898 en el taller de Ortega Hermanos hasta que se retiró en el año 1926, cuando el taller estaba en manos de la Compañía Gral. de Fósforos.

Además, este personal disfrutó de estabilidad económica, derivada de la modalidad de percibir sus salarios mensualmente. Estos salarios mensuales incluyeron el pago de los días festivos o de paro técnico en el departamento o

por su padre, el mismo está ubicado en las calles Santo Domingo y San Antonio del barrio de Barracas. sección, un privilegio que no compartieron los hombres de oficio cuyos salarios estaban calculados por día. Por otro lado, la remuneración y otros aspectos del contrato era una negociación individual entre patrón y capataz, quienes quedaron al margen de la negociación colectiva de la Comisión Mixta Gráfica.

Los empresarios valoraron a sus supervisores por los aportes concretos realizados a los intereses de la empresa. Por lo general estaban encargados de mantener una disciplina que contribuyera al aumento o por lo menos al mantenimiento del ritmo de trabajo, que ya no era el del trabajo artesanal. De acuerdo con esto, la dirección intermedia tuvo a su cargo la tarea de barrer con la tradicional independencia en el trabajo del hombre de oficio, para colocar la organización laboral bajo la autoridad del capataz.

Los asalariados regularmente preparados, que por lo general, al confeccionar un trabajo procuran desarrollar con independencia sus facultades artísticas y dan vuelo a su imaginación para comunicar belleza al trabajo que realizan y libre curso a las fantasías que sienten en el molde que le dan para componer, se ven totalmente cohibidos de hacerlo, porque el repentino Miguel Angel, con su retina infalible, todo lo ve tosco y burdo, es decir, la estética de todos los trabajos que no sean hechos bajo su inmediata dirección. ${ }^{36}$

36 "El capataz", El Obrero Gráfico, 1 de septiembre de 1908 , p. 5. 
Los regentes, encargados, jefes de secciones y capataces tuvieron un creciente poder en la contratación del personal. Ellos decidían cuántos y quiénes entraban a trabajar en las secciones bajo su dirección. También eran los responsables de seleccionar el personal a despedir cuando había un descenso en la cuantía del trabajo en el taller. Cuando se producía una huelga, eran los encargados de contratar y despedir, una tarea que los colocaba abiertamente frente a los trabajadores como "hombres del patrón". En esas circunstancias, los jefes y capataces se ocupaban de reclutar los esquiroles que reemplazarían a los obreros en conflicto. Y una vez finalizado el conflicto, eran ellos los encargados de despedir a los obreros más comprometidos con el movimiento huelguístico. Un claro ejemplo de lo afirmado fue lo sucedido durante los quince días que duró el conflicto de 1908 en el taller. Los capataces de Ortega y Radaelli se adhirieron durante el conflicto a la idea de su supuesta condición de "hombres que están en el medio", ni pertenecientes a la categoría de los trabajadores ni a los patrones, sin embargo los trabajadores los asociaron a la dirección empresaria:

todos ellos se han prestado a reclutar personal, y algunos, los de la sección máquinas tipográficas, han hecho más, trabajaron como verdaderos animales de día y de noche. No hay duda que son elementos neutrales. ${ }^{37}$

${ }^{37}$ El Obrero Gráfico, 1 de agosto de 1908, p. 7.
LA CONTRATACIÓN DE TRABAJADORES:

DE LA RECOMENDACIÓN A LA

PRESENTACIÓN SINDICAL

Seguramente algunos trabajadotes ingresaron a Ortega y Radaelli a través de un aviso del periódico, otros recurrieron directamente a la puerta del establecimiento para solicitar una vacante laboral. Pero la mayoría utilizó otro mecanismo de ingreso: la recomendación. Para que esta modalidad de gestión del acceso a los puestos de trabajo pudiese funcionar era necesaria la existencia de un universo de parientes, connacionales o vecinos empleados en el establecimiento. $\mathrm{O}$ bien, algún contacto más indirecto, de alguien que a su vez tuviese un conocido que trabajaba en el taller dispuesto a hacer de intermediario en la búsqueda del empleo.

Este mecanismo funcionó, y con bastante eficacia. El número de trabajadores recomendados ascendió a 248 , y pudimos cuantificarlo porque quedó registrado en el libro de personal, en un ítem específico en el que se escribía el apellido de aquel que recomendaba. La cifra alcanza a 300 si se incluyen los 52 operarios que ingresaron a través de la Federación Gráfica Bonaerense, pero que diferenciamos porque esta vía de ingreso está relacionada con el peso del sindicalismo de oficio en la contratación de personal; volveremos después sobre esta idea.

De un total de 631 legajos reconstruidos, la mitad correspondieron a personas contratadas por recomendación, aunque no siempre declarada explícitamente. En muchos casos en que no se explicita ninguna recomendación, pudimos observar que había fun- 
cionado este mecanismo. Por ejemplo entre trabajadores que compartían un mismo apellido y mostraban lazos de parentesco. En otros casos, la constatación del apellido de la esposa -también registrado- nos muestra los entrecruzamientos familiares entre trabajadores del taller y la posibilidad de que uno de ellos fuese el enlace para ocupar un puesto. Otras veces, igual lugar de procedencia o un domicilio compartido nos persuadió, para aquellos casos en que no estaba explicitada la modalidad de ingreso, que alguien había gestionado el contacto entre la empresa y el futuro trabajador. ${ }^{38}$

En el caso de los hermanos Fuscos -aprendices de encuadernación-, de los tres que trabajaron en distintos momentos entre los años 1914 y 1919 , dos entraron aparentemente sin ningún contacto previo, sin embargo, como lo hicieron con un año de diferencia, pensamos que Santiago, el primero en ser contratado, gestionó el empleo de Antonio en 1915. Los hermanos Falcó y Onofrio Fabiano -trabajadores de la sección encuadernación- vivieron en el mismo domicilio; de los tres, el primero en ingresar fue Prudencio, en junio de 1905; los demás entraron en noviembre de ese año sin recomendación, pero seguramente fue el hermano quien gestionó sus ingresos. Los tres hermanos González ingresaron aparentemente sin ninguna recomendación, y constituyeron una estirpe dentro de la sección litográfica; el primero que

38 Sobre la persistencia del sistema de contratación utilizando una red social encabezada por parientes véase Thompson, "Jugando", 1989, pp. 105-139. trabajó como maquinista litográfico fue Luis, desde 1909, un año después ubicó a su hermano Emilio, y digo ubicó, porque fue seguramente por injerencia de su hermano que ocupó una vacante de oficial maquinista, y luego hacia 1912 habían colocado a su hermano menor como sacapliegos litográfico. En impresión tipográfica, los hermanos Manuel y Mariano García, nacidos en Úbeda: el primero entró en enero de 1904, el segundo en abril del mismo año, seguramente por gestión de su hermano, aunque figura sin recomendación. En el caso de los hermanos Pedro y Santiago Díaz, el primero era un fotograbador; ingresó en 1905 , y su hermano fue contratado en 1915 como aprendiz de grabado. Podríamos continuar con más ejemplos, pero los expuestos hasta aquí nos parecieron suficientemente esclarecedores para afirmar que existió un universo más amplio de recomendaciones que las registradas en el registro de personal.

Para ingresar a un taller gráfico se necesitaban las calificaciones técnicas, pero también era casi imprescindible conocer a alguien que estuviese dentro del establecimiento. ¿Por qué los dueños del establecimiento prefirieron esta modalidad para la selección de los trabajadores? Esta política de personal tuvo como objetivo un mejor conocimiento de los aspirantes a un puesto de trabajo, sus "antecedentes personales, familiares, sociales y políticos". Dichos aspectos, que tiempo después tomaron a su cargo las oficinas de personal encargadas de estudiar, analizar y realizar los informes ambientales previos a la contratación de cada uno de los candidatos a un puesto de trabajo, 


\section{SECUENCIA}

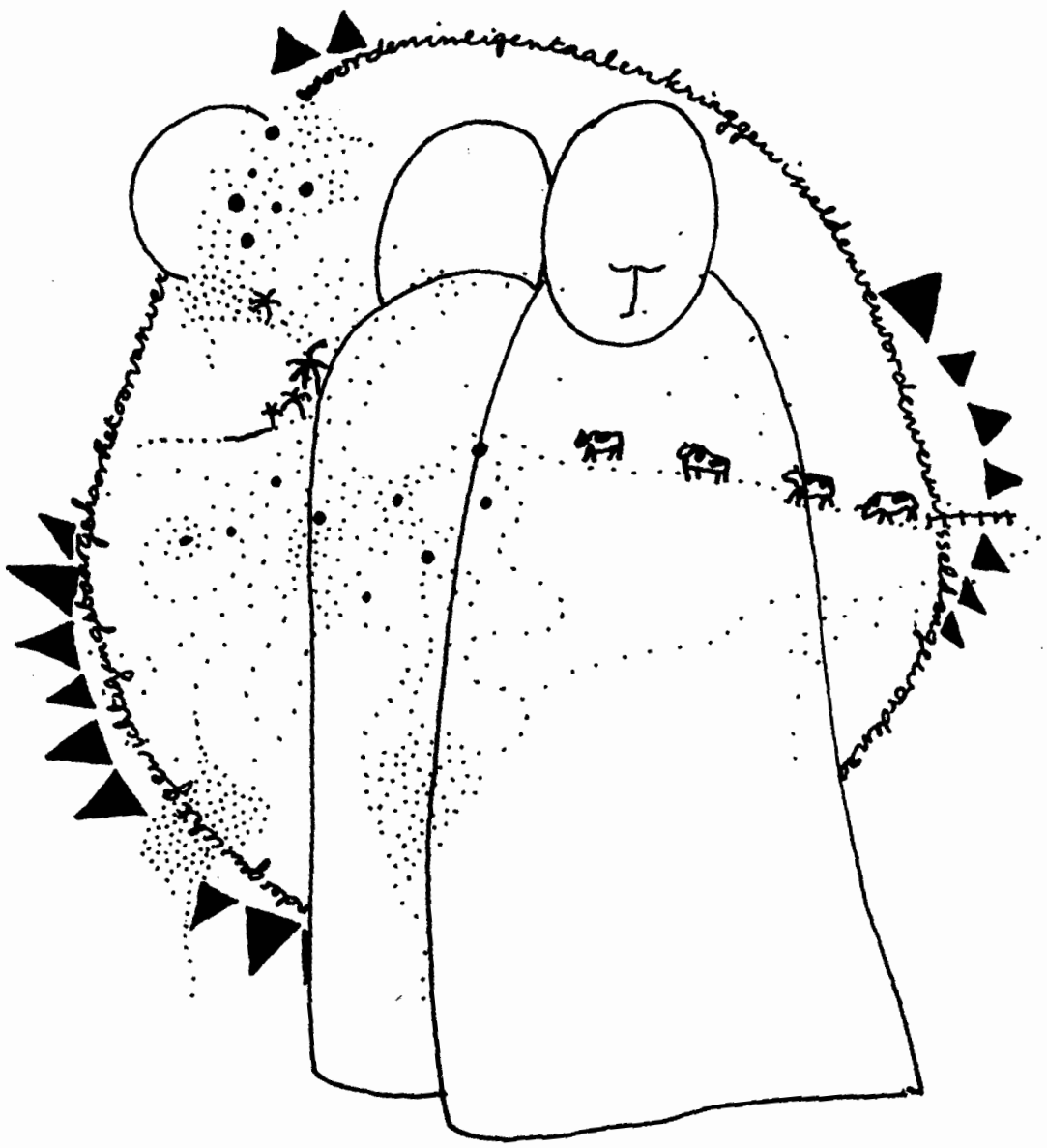


exan cubiertos en esta época por esta vía de ingreso, que intentaba garantizar la conducta de sus recomendados. La dirección de la empresa estaba esperanzada en reforzar la fidelidad a la misma, el despido de un trabajador podía significar la pérdida del trabajo por otros familiares. Desde la perspectiva empresarial, había una creencia muy arraigada de que esta modalidad de suministrar mano de obra creaba lealtades hacia los patrones, y por tanto era más fácil obtener algún éxito en la imposición de la disciplina laboral y amortiguar los conflictos entre capital y trabajo. ${ }^{39}$

¿Quiénes podían ejercer ese juego de influencias para contratar trabajadores? En primer término, hemos podido observar que los ingresados por

39 La utilización de los archivos de fábrica -Pirelli Argentina- permitió a Barbero desentrañar el papel desempeñado por las cadenas migratorias en los mecanismos de reclutamiento (vía la recomendación) de la mano de obra de la empresa. En este caso estaríamos frente a una estrategia deliberada de la empresa con el objeto de transmitir una imagen de fraternidad o gran familia italiana en el seno de la Pirelli que ayudase a atenuar los conflictos. Por el contario, Lobato ha señalado, en su estudio sobre las empresas cárnicas de la ciudad de Berisso, que las modalidades de ingreso de la fuerza laboral tienen que explicarse en el contexto de la adopción por las empresas de formas organizativas del trabajo con criterios tayloristas. Si bien a través de los registros pudo observar la presencia de varios integrantes de una familia compartiendo el espacio laboral, esta presencia no estuvo ligada a la recomendación como política empresaria de contratación para amortiguar conflictos. Véase Barbero, "Obreros", 1992, pp. 189-203, y Lobato, "Visión", 1992, pp. 205229. influencia directa de los dos dueños del taller fueron minoritarios. Entre los recomendados por Radaelli figuraban nueve y por Fausto Ortega cinco. Este escaso número pudo obedecer a los cambios en las funciones de los dueños de los talleres multigráficos, cada vez más ocupados en la marcha de los negocios y, a su vez, más alejados del control y supervisión del acontecer cotidiano en las secciones y de la gestión de la mano de obra. También antiguos trabajadores del establecimiento tuvieron influencia para facilitar un puesto de trabajo, por ejemplo, a través de la recomendación de Luis Arata, un antiguo encuadernador, ingresaron unos 17 trabajadores a la sección, la mayoría adolescentes empleados como aprendices.

Una cuarta parte de los recomendados fue presentada directamente por alguno de los supervisores, ya sea para ocupar un puesto en la sección que dirigían ellos o bien en otras, de acuerdo con el oficio del postulante. El capataz de encuadernación recomendó a 17 trabajadores de distintas categorías para puestos de trabajo de su sección. Las tramas familiares de los capataces se extendían por varias secciones, entre los recomendados por ellos, hemos observado la presencia de miembros de la familia en otros puestos de responsabilidad. El caso más ejemplificador fue el de los Trentalance. Nicolás Trentalance fue capataz de encuadernación, ingresó al establecimiento en 1902; al frente de la sección depósito de papel, con el cargo de capataz, se encontraba Genaro Trentalance, ingresado en 1906 y, por último, en fotograbación, F. G. Trentalance, como oficial, tuvo asignada una de las tarifas sala- 
riales diarias más elevadas de dicha sección.

Por lo general los trabajadores recomendados por los regentes o capataces para puestos en las secciones bajo su supervisión fueron obreros protegidos por ellos. Este personal quedó al margen de la tiranía de los capataces, quienes provocaban con sus abusos y conductas arbitrarias conflictos en una parte del personal a sus órdenes.

En el ámbito laboral fue habitual la protección brindada por los capataces a sus connacionales ubicados por debajo de su dirección. El Obrero Gráfico expresaba así esta situación:

notándose que la mayoría de los encargados pertenecen a las diversas nacionalidades de Europa; esto no tendría nada de particular, si no fuera que estos señores capataces, haciendo gala de un egoísmo exagerado y un patriotismo absurdo y contrario a todo sentimiento humanitario, procuran rodearse de sus connacionales, mejorándoles en todo lo posible, mientras a los que no tienen la suerte de haber nacido en la patria del ignorante mandón, los trata con desprecio, poniéndolos en la picota, por cualquier causa, con sus paisanos; les da los peores trabajos con el pretexto de que no saben nada $\mathrm{y}$, despidiéndolos por alguna insignificante nimiedad, concluyen por dividir a los obreros en dos bandos. 40

Como contrapartida, los supervisores esperaban una cuota de fidelidad hacia su persona, fundamentalmente

40 "El capataz", El Obrero Gráfico, 1 de septiembre de 1908, p. 6. cuando se trataba de imponer la autoridad empresarial a través de ellos, sobre cuestiones de organización del trabajo que significaban una embestida contra los oficios. En suma, los dueños del establecimiento estaban persuadidos de que a través de esta vía de ingreso, y en especial la recomendación de los capataces, evitaban la presencia de obreros cercanos a la organización sindical gráfica para limitar el desarrollo de una solidaridad obrera que exigiese el cumplimiento de las reglas establecidas sobre la jornada de ocho horas y horario máximo de trabajo diario, clase de trabajos según categoría y un programa de salarios mínimos y de producción diaria máxima para cada trabajador, entre otras.

Pero, a su vez, los trabajadores y la organización sindical utilizaron la "presentación" para recomendar operarios muy familiarizados con las costumbres y actitudes sociales del oficio, cuyas conductas frente al trabajo contribuyeran a evitar la inferiorización de las condiciones laborales. Si bien ingresaron a través de los lazos familiares, parentesco, amistad y vecindad, las lealtades de los trabajadores calificados estaban más ligadas a los intereses del oficio que a otras, incluida la de la empresa. Seguramente fueron recomendados porque los reconocían como "operarios respetables", además de parientes o amigos. Como "operarios respetables" fueron incapaces de atender más de una máquina, realizar trabajos que no correspondieran a su categoría, producir por encima de lo acordado y comenzar el trabajo antes que los otros compañeros de la sección. Todo un conjunto de hábitos, costumbres y re- 
glamentaciones de comportamiento, aprendidos y transmitidos en el taller o en la vida social fuera del mismo; en las charlas informales cercanas a los ámbitos de trabajo, ya que los trabajadores gráficos tendieron a vincularse entre sí más allá del espacio laboral, y en las reuniones más formales del sindicato de oficio o la sociedad mutual.

Por otro lado, en un mundo laboral que no contó con un sistema de aprendizaje fuertemente pautado, la presentación, en el caso de los aprendices, operó como control para saber quiénes ingresaban a los oficios. Es decir, como una pieza clave frente al reclutamiento indiscriminado de mano de obra. Este joven llevado al taller de la mano del padre $u$ otro pariente estaba familiarizado con el mundo laboral gráfico antes de ingresar, sobre todo no le eran ajenas las reglas y códigos que regían entre trabajadores. El aprendiz sabía del respeto a la norma sancionada en los convenios, por tanto, no realizaba aquellas tareas que no eran propias de su categoría. A través de esta "modalidad" de ingreso al oficio, estaba garantizada la resistencia a una de las prácticas más usuales de los capataces, la contratación de jóvenes semiformados, a los que se les pagaban salarios inferiores, para llevar adelante trabajos correspondientes a operarios de mayor jerarquía en el oficio. Una forma más de resistencia frente a la degradación de los oficios.

Si bien esta manera de suministrar personal brindaba un cierto control por parte de los trabajadores, los mismos propusieron una alternativa al modelo empresarial, y éste fue la contratación de obreros sindicalizados:
Nuestro sindicato ha expresado reiteradamente su anhelo de que en los talleres sólo trabajen los obreros que previamente se comprometan a no hacerlo en condiciones inferiores a las determinadas en nuestro Convenio; ¿y quiénes son esos obreros? Claro es que, salvo excepciones, no son los obreros que acuden al llamado de un aviso que leen en el diario, como tampoco lo son los que obtienen trabajo debido a su mayor confianza con tal o cual capataz, pero sí pueden serlo, y lo son para nosotros, los obteros asociados. 41

La obligatoriedad de la agremiación para trabajar en los talleres tenía como propósito impedir la entrada de obreros no organizados, que aceptaban una ocupación en condiciones de trabajo y tarifa inferiores a las del Convenio. Porque la incorporación de un trabajador no sindicalizado implicaba la entrada de un operario falto de capacidad para defender el valor de su fuerza de trabajo. Desde 1908 y hasta 1915 la Federación, a través de la delegación obrera encargada de discutir la renovación periódica del Convenio, presentó la demanda del reconocimiento de la organización sindical por parte de los patrones y, dentro de ella, la cláusula que obligaba a los industriales a ocupar obreros sindicalizados. En 1915 la exigencia fue más categórica y obtuvieron una victoria parcial. Un triunfo parcial, porque no pudieron imponer totalmente la política del

1 Ver nota de la delegación obrera presentada ante la Comisión Mixta Gráfica, BUIA, 15 de octubre de 1917 , p. 41. 
closed shop o taller cerrado a los no sindicalizados. Sin embargo, se llegó a establecer un dispositivo legal que aseguraba la "gestión" de la organización en el mercado laboral para los obreros a contratar, estableciendo en el artículo tercero que

los componentes de la Sección Artes Gráficas de la Unión Industrial Argentina no tomarán, después de la sanción de este Convenio, obreros nuevos que no sean socios efectivos de la Federación Gráfica Bonaerense (Sociedades Unidas). Por su parte, la Federación Gráfica Bonaerense (Sociedades Unidas), se compromete a que sus asociados no trabajen en los establecimientos que no pertenezcan a la Sección Artes Gráficas de la Unión Industrial Argentina en condiciones de remuneración o de horario inferiores a las establecidas en el Convenio vigente entre ella y la Sección Artes Gráficas de la Unión Industrial Argentina. ${ }^{42}$

El número de trabajadores calificados próximos o miembros de la Federación Gráfica Bonaerense y a su vez socios de la Sociedad Tipográfica Bonaerense -mutualismo de oficio-, que estaban empleados en el taller Radaelli, fue importante. A los fines de nuestra investigación nos interesamos por aquellos ingresados por influencia del sindicalismo de oficio a partir de la puesta en práctica de la cláusula del Convenio firmado en 1915. En el registro de personal del establecimiento estudiado pudimos observar que en el ítem "presentado" quedaron registrados 52 nuevos trabajadores ingresados

42 BUIA, 15 de marzo de 1916, p. 18. por la gestión de la Federación Gráfica Bonaerense. Sobre ese total de incorporaciones a puestos laborales por gestión directa de la organización sindical, correspondieron trece a las diversas categorías de la sección encuadernación; diez a litografía; once a composición; catorce a impresión tipográfica; tres a fotograbado y un último sin identificar el oficio. A juzgar por estos datos, el peso de la influencia sindical estuvo dada en aquellos oficios que tradicionalmente tuvieron una mayor sindicalización. ¿Los ingresos de trabajadores sindicalizados se produjeron inmediatamente después de la firma del Convenio en 1915? Por los datos obtenidos parece que pasaron unos años, dado que de esos 52 trabajadores más de la mitad ingresó durante 1919 y el resto durante 1920 .

Dato relevante el de la fecha, porque el año 1919 fue un momento de gran rotación de personal en el taller, durante ese año entraron 142 trabajadores y salieron 72 . En ese contexto de rotación de personal, $21 \%$ del total de nuevos operarios ingresaron por recomendación del sindicalismo de oficio.

Esta gestión de la Federación puede considerarse exitosa, teniendo en cuenta que fue llevada adelante en un año de intensa conflictividad obreropatronal en el sector gráfico. ${ }^{43}$ Estos

${ }^{43}$ Durante el primer semestre de 1919 los gráficos lucharon por aumentos de salarios y reducción de la jornada laboral a 44 horas semanales para la jornada diurna y 39 horas para la nocturna. En febrero de ese año, con motivo de numerosas huelgas por aumentos salariales, los patrones decidieron la anulación del Convenio de Trabajo vigente durante doce años. En ese semestre los 
conflictos por reivindicaciones propias de los gráficos o de solidaridad con otros sectores obreros nos permitieron ampliar la explicación acerca de la gran rotación de personal del año 1919. La gran mayoría de los egresos estuvieron comprendidos en ese semestre de huelgas y otros inmediatamente después, un ejemplo fue el de Ruggiero Rúgilo, dirigente gráfico y tipógrafo en Radaelli; había ingresado en febrero de 1919 y fue despedido apenas finalizado el movimiento solidario. Sin embargo, la Federación mantuvo el control sindical sobre parte del personal contratado luego de la finalización del conflicto; los trabajadores presentados por la Federación ingresaron entre junio y diciembre de 1919 . Este control fue ejercido el año siguiente. En el año 1920 también hubo una intensa rotación de personal, y en ese movimiento de ingresos-egresos fueron contratados alrededor de 20 trabajadores presentados por la organización sindical gráfica.

trabajadores gráficos se plegaron al movimiento de boicot a la firma Gath y Chaves, en el marco de la huelga de empleados de comercio. Como observó Marotra, el boicot fue una iniciativa de la FORA, y el peso del movimiento recayó en dos organizaciones sindicales, la FoM, que se negó a cargar-descargar mercaderías con destino a Gath y Chaves, y la Federación Gráfica Bonaerense, cuya medida impidió la confección de la propaganda para la gran tienda. Entre los talleres de imprenta comercial, Radaelli fue paralizado porque en este establecimiento se confeccionaban todos los catálogos de propaganda de Gath y Chaves y los trabajadores cumplieron con la medida de boicot. El clima conflictivo del primer semestre del año 1919 alcanzó a la organización patronal, hubo una división en las filas de los grandes impreso-

\section{COMENTARIO FINAL}

Los cambios en las artes gráficas en general, y en el establecimiento Ortega y Radaelli en particular, tendieron a adaptar el detallado trabajo artesanal a ritmos rápidos y más complejos. La multiplicidad de procesos laborales, la incorporación de maquinaria y la división del trabajo acentuaron la presencia de una mano de obra heterogénea en cuanto a oficios y calificaciones de la imprenta. También constatamos la incorporación de trabajadores calificados pero de oficios no ligados a las artes gráficas, y el comienzo de una demanda muy reducida de mano de obra más homogénea, sin calificación e intercambiable en diversos puestos de trabajo y secciones. ${ }^{44}$

La adaptación a una compleja organización laboral no barrió con todos los oficios tradicionales, con una larga perdurabilidad dentro de esta rama industrial. Ciertas transformaciones, como la introducción de nuevas tecnologías en la tipografía y la impresión, dieron lugar a la aparición de nuevos oficios o especialidades. En la encuadernación las nuevas modalida-

res. Por un lado estaban aquellos socios de la Sección Artes Gráficas de la uia cuya opinión era favorable a los doce años de vigencia de las tarifas salariales y el reglamento de trabajo para las imprentas, por eso perseguían una política de acercamiento con la Federación, otros en cambio, mantuvieron una posición de ruptura de relaciones con la organización de oficio. Véase Marotta, Movimiento, 1961, t. II, Pp. 249-256.

44 Véase Sabato y Romero, Trabajadores, 1992, pp. 194-217, y Falcón, Mundo, 1986, pp. 102118. 
des de subdivisión del proceso laboral originaron cambios en el contenido de las categorías y calificaciones de los trabajadores. Durante el periodo de estudio la industria gráfica demandó una mano de obra calificada, y los trabajadores de los oficios gráficos continuaron teniendo una presencia mayoritaria dentro del taller.

En cuanto a la composición de la fuerza laboral por nacionalidad, encontramos una presencia mayoritaria de trabajadores nativos en los oficios de la imprenta, aunque observamos la existencia de una mayor diversidad de nacionalidades entre los trabajadores, en una industria que hasta el último cuarto del siglo XIX estaba formada casi en exclusividad por argentinos. ${ }^{45}$

La reconstrucción parcial de los datos cuantitativos y la contrastación con fuentes cualitativas muestran la presencia de un sector de personal jerárquico. En nuestro trabajo destacamos la influencia que tuvieron los capataces en la contratación de personal. Al facultar los dueños de talleres a ese colectivo de dirección para la realización de la gestión de personal, una de las actividades que hasta esos momentos

45 Nuestra reconstrucción confirmó la afirmación hecha en 1909 en el informe publicado en el Boletín del Departamento Nacional del Trabajo sobre las condiciones de trabajo en imprentas y litografías; en dicho informe se aseguraba que existió un movimiento continuo de gráficos de países limítrofes, Uruguay y Brasil, y por otra parte de los países europeos, mayoritariamente Italia y España. Publicado en el Boletín del Departamento Nacional del Trabajo, 30 de septiembre de 1909 , p. 327. les era propia, le dio un gran poder frente al conjunto de los trabajadores. La fuerza adquirida por regentes y capataces para tomar y despedir trabajadores estuvo inscrita en una política de gestión empresaria del personal, que tenía como objetivo romper la solidaridad obrera de oficio que disputaba por esos años, debido a los cambios sucedidos en las artes gráficas, el control de la organización del trabajo.

Las redes familiares, de amistad y connacionales fueron algunos de los medios utilizados para alcanzar la recomendación o "presentación", importante modalidad de ingreso al trabajo. Los patrones quisieron explotar a su favor las lealtades familiares o étnicas que se originaban a partir de la recomendación, pero evidentemente esas lealtades se conjugaron con una fuerte identidad y conciencia de oficio, que se expresó a través de una solidaridad del grupo laboral en la defensa de una tradición de altos salarios y seguridad en el puesto.

La presentación, en manos de los trabajadores calificados, sirvió para controlar quiénes ingresaban al establecimiento y oficio, para garantizar la incorporación de obreros capaces de llevar adelante la defensa de sus intereses. El control ejercido por parte de los trabajadores a través de esta modalidad de incorporación de la fuerza laboral fue bastante eficaz para asegurar la presencia de trabajadores muy próximos a la organización sindical y hacer cumplir a los empresarios las cláusulas del convenio referidas a la contratación de trabajadores sindicalizados. El objetivo era el establecimiento del "taller 
cerrado" para los no sindicalizados como medio de garantizar el cumplimiento del Convenio y Tarifa Salarial. Esta trayectoria de los trabajadores calificados de las imprentas en los primeros 20 años del siglo Xx, trazó el rumbo de la negociación que seguiría el sindicalismo gráfico por varias décadas. ${ }^{46}$

\section{ARCHIVOS \\ AECGF-CGFF Archivo Empresarial Compañía General de Fósforos-Compañía General Fabril Financiera \\ FG Fundación Gutenberg \\ HBN Hemeroteca de la Biblioteca Nacional}

\section{HEMEROGRAFÍA}

El Obrero Gráfico, 1907-1915

La Vanguardia, 1900-1915

La Protesta, 1906, 1907, 1908

46 Un ejemplo de ello lo encontramos en Talleres Gráficos Fabril Financiera, tal vez habían heredado la experiencia de Radaelli, dado que ese taller se formó con gran parte del personal del establecimiento estudiado por nosotros al ser comprado en 1921 por el grupo empresarial italiano Compañía General de Fósforos. En la década de los treinta en este taller que ocupaba 2000 trabajadores gráficos estaban todos afiliados a la Federación, porque no se podía "ingresar al establecimiento si no se exhibía el carnet de la Federación Gráfica Bonaerense", véase la entrevista al dirigente gráfico René Stordeur realizada por Luis Alberto Romero para el Proyecto de Historia Oral, Instituto Torcuato Di Tella, 1970-1971, p. 201.

\section{BIBLIOGRAFÍA}

-Badoza, María Silvia, "El ingreso de la mano de obra femenina y los trabajadores calificados en la industria gráfica" en Lidia Knecher y Marta Panaia (comps.), La mitad del país. La mujer en la sociedad argentina, Bibliotecas Universitarias-CEAL, Buenos Aires, 1994. , “Tipographical Workers and Their Mutualist Experience: The Case of the Sociedad Tipográfica Bonaerense, 1857-80" en Jeremy Adelman (comp.), Essays in Argentine Labour History, 1870-1930, The Macmillan Press, Houndmills y Londres, 1992.

-Barbero, María Inés y Susana Felder, "Los obreros italianos de la Pirelli Argentina (1920-1930)" en Fernado J. Devoto y Eduardo Míguez, Asociacionismo, trabajo e identidad étnica. Los italianos en América Latina en una perspectiva comparada, CEMLA/CSER/IEHS, BUenos Aires, 1992.

-Bilbao, Andrés, "El proceso de trabajo en artes gráficas: tecnología y descentralización productiva", Sociología del Trabajo-Nueva época, núm. 9, primavera de 1990.

- Tercer Censo Nacional de la República Argentina, 1914, Rosso, Buenos Aires, 1917.

-Derry, T. K. y Trevor Y. Williams, Historia de la tecnología, Siglo XXI Editores, Madrid, 1977, vol. 3.

-Duarte, Ángel, "Mayordomos y contramaestres. Jerarquía fabril en la industria algodonera catalana, 1879-1890", Historia Social, núm. 4, primavera-verano, 1989.

-Falcón, Ricardo, "Aspectos de la cultura del trabajo urbano. Buenos Aires y Rosario, 1860-1914" en Diego Armus, Mundo urbano y cultura popular. Estudios de bistoria social argentina, Sudamericana, Buenos Aires, 1990 .

El mundo del trabajo urbano (1890-1914), Ceal, Buenos Aires, 1986. 
-Lobato, Mirta, "Una visión del mundo del trabajo: obreros inmigrantes en la industria frigorífica, 1900-30" en Fernado J. Devoto y Eduardo Míguez, Asociacionismo, trabajo e identidad étnica. Los italianos en América Latina en una perspectiva comparada, CEMLA/ CSER/IEHS, Buenos Aires, 1992.

-Marotta, Sebastián El movimiento sindical argentino. Su génesis y desarrollo, Ediciones "Lacio", Buenos Aires, 1961.

-Molina, Carles Enrech, "La reforma de la organización del trabajo en 'La España Industrial' a finales del siglo XIx", Sociología del Trabajo-Nueva época, núm. 29, invierno 1996-1997.

-Pianetto, Ofelia, "Mercado de trabajo y acción sindical en la Argentina, 18901922", Desarrollo Económico, núm. 94, vol. 24, julio-septiembre de 1984.

-Rule, John, Clase obrera e industrialización. Historia social de la revolución industrial británica, 1750-1850, Crítica, Barcelona, 1990.

-Sábato, Hilda y Luis Alberto Romero, Los trabajadores de Buenos Aires. La experiencia del mercado: 1850-1880, Sudamericana, Buenos Aires, 1992.

-Thompson, Paul, "Jugando a ser trabajadores cualificados. Cultura de fábrica y enorgullecimiento por la cualificación laboral entre los obreros del automóvil de Coventry", Sociología del Trabajo-Nueva época, núm. 7, otoño 1989.

-Wilentez, Sean, Chants Democratic. New York City and the Rise of the American Working Class, 1788-1850, Oxford University Press, Nueva York, 1984.

-Zimbalist, Andrew, "Technology and the Labour Process in the Printing Industry" en Andrew Zimbalist (comp.), Case Studies on the Labor Process, Monthly Review Press, Nueva York, 1979.

\section{GLOSARIO}

Composición. Copia de un texto a líneas de plomo derretido para la impresión.

Corrección. Lectura inicial del texto compuesto para advertir sus posibles errores y omisiones. La tarea lleva a rehacer e intercalar las líneas erróneas.

Cuerpo. Tamaño y características de la letra de imprenta elegida para componer el texto. Encuadernación. Conjunto de operaciones manuales o ejecutadas a máquina cuyo fin es encuadernar libros, registros, catálogos, etc. Taller o departamento de una industria gráfica equipado para la encuadernación.

Estereotipia. Procedimiento empleado para obtener planchas de impresión de metal de aleación tipográfica mediante duplicación de formas tipográficas de tipos movibles, con grabados o sin ellos. Consiste en vaciar una aleación tipográfica de una composición específica sobre una matriz de papel encolado con la impronta de la forma que hay que duplicar. La estereotipia es el procedimiento de duplicación más rápido y económico de las formas tipográficas. Sirve para preservar la forma original y para tener a disposición formas futuras sin necesidad de inmovilizar caracteres y fotograbados.

Fotograbado. Plancha de metal o material plástico con relieve en la que se ha grabado una fotografía mediante un método de luz y de productos químicos. También denominado fotorreproducción tipográfica.

Galerada. Prueba inicial de un texto que se obtiene para advertir posibles errores en la composición. Se hace habitualmente en una tira de papel, dando entrada a una sola columna del texto impreso, a cuyos costados se anotan las correcciones.

Grabado. Acción o efecto de grabar. Figura en hueco o en relieve conseguida en una su- 
perficie de madera, piedra litográfica o metal. El grabado químico sobre metales, ayudando por ácido nítrico al trabajo manual del buril para dar profundidad y distintas texturas al dibujo. Con destino a la impresión tipográfica.

Heliografía. Reproducción de originales sobre soportes transparentes mediante la exposición a la luz del mismo original a través de una capa fotosensible transparente, por contacto.

Impresión. Conjunto de procedimientos tecnológicos para la reproducción de originales gráficos. Se trata del proceso de pasar al papel, en cientos o miles de ejemplares, los textos o grabados. En el proceso tradicional de impresión por contacto, el plomo entintado es presionado sobre el papel.

Justificar. El término justificar es empleado para ajustar toda una página en su correspondiente rama.

Linotipo. Máquina para la composición en plomo que produce cada línea en una sola pieza. Mediante un teclado similar al de una máquina de escribir, los tipos móviles (matrices) caen sobre una regleta, que luego es presionada sobre el plomo derretido. Los tipos móviles vuelven automáticamente a sus cajas de origen.

Litografía. Proceso gráfico caracterizado por la impresión directa con formas planas de piedra o metal, donde la tinta queda adherida a los puntos necesarios de una imagen.
Matrices. Tipos móviles de metal, uno de cuyos bordes dibuja una letra para modelar después a presión el plomo derretido.

Monotipia o monotipo. Máquina de componer con tipos sueltos.

Prensa. Nombre que recibe la máquina con la que se realiza la impresión, cualquiera que sea el procedimiento empleado.

Rama. Marco rectangular de hierro o acero del tamaño de una hoja de diario. Colocado sobre una mesa, permite disponer el plomo de texto y grabados, de acuerdo a un diagrama previsto, afirmándolo después con un sistema de barras y tornillos.

Rotativa. Máquina de tamaño considerable, que combina cilindros de impresión, cilindros de papel y depósitos de tinta. Sustituye a la anterior máquina plana, que obligaba a colocar separadamente las hojas lisas de papel contra el relieve de plomo.

Tipografía. El operario elige y coloca en una regleta las matrices de letras y signos para componer con ellas un texto. Con la regleta así dispuesta se confecciona cada una de las líneas de plomo. El tipógrafo se ocupa habitualmente de los titulares en grandes cuerpos de letras, mientras los más pequeños quedan a cargo del linotipista. El tipógrafo se ocupa de colocar el plomo en la página o rama e introduce allí las correcciones necesarias. El operario para componer elige las matrices en diversas cajas para diferentes estilos y tamaños de letras, por ello se le denomina cajista. 